\title{
Characterisation of Ballina clay
}

\author{
J. A. PINEDA*, L. P. SUWAL*, R. B. KELLY*, L. BATES* and S. W. SLOAN*
}

\begin{abstract}
This paper describes a comprehensive characterisation study carried out on clay from the National Soft Soil Testing Facility located at Ballina in northern New South Wales (NSW, Australia). Ballina clay represents the estuarine soft clays of high to extremely high plasticity from the Richmond river valley in NSW. They are structured and lightly overconsolidated with an average organic content around 3\%. Index properties as well as mechanical parameters were estimated from laboratory tests performed on tube specimens retrieved using a fixed-piston sampler. Index characterisation tests were combined with constant rate of strain tests, incremental loading tests and stress-path triaxial testing to evaluate compressibility, stiffness, permeability and strength parameters. These deposits display very high compressibility and a low undrained shear strength which is larger in triaxial compression. Ballina clay shows a non-linear stress-strain response either in one-dimensional compression or undrained shearing. The consolidation coefficient, and consequently the water permeability, reduces dramatically with the stress level in the overconsolidated zone, mainly due to soil destructuration. A brittle response has been observed during shearing that reduces the undrained shear strength by around 50\% after peak. Geotechnical profiles describing the variation of index and mechanical properties with depth are provided and compared against in situ test results. It is shown that the use of the fixed-piston sampler, in combination with non-destructive methods, to assess and select samples for laboratory testing provided good quality and reliable test results which are in agreement with data interpreted from in situ tests.
\end{abstract}

KEYWORDS: clays; compressibility; in situ testing; laboratory tests; sampling

\section{INTRODUCTION}

The establishment of the Australian Research Council Centre of Excellence for Geotechnical Science and Engineering (CGSE) has provided an opportunity for carrying out fundamental research aimed at providing solutions to problems associated with energy and transport infrastructure in Australia. Of particular interest is the proper understanding of the mechanical behaviour of natural estuarine soft clays, commonly found along the eastern and southern Australian coastlines, which serve as the foundation soil for much of the country's geotechnical infrastructure. Low in situ stresses and undrained shear strength, a high compressibility, the presence of electrolytes in the pore fluid, the presence of organic matter and expansive minerals, as well as weak cementation are typical features of these natural soft clays. Not surprisingly, these characteristics pose a number of challenges for proper geotechnical characterisation, either in situ or in the laboratory. The establishment by the CGSE of a National Soft Soil Field Testing Facility (NFTF) at Ballina (NSW) (Kelly, 2013) has allowed high-quality in situ testing and monitoring, combined with advanced laboratory testing, to characterise a typical Australian estuarine soft clay with the goal of improving engineering design methods.

This paper presents the results of a comprehensive experimental study aimed at characterising the materials composing the soil profile at the Ballina site (hereafter called Ballina clay). It comprises thick deposits of soft estuarine clay that infills the Richmond River valley in northern New South Wales. Index properties as well as mechanical parameters have been interpreted from laboratory tests

Manuscript received 23 August 2015; revised manuscript accepted 18 January 2016. Published online ahead of print 2 March 2016.

Discussion on this paper closes on 1 December 2016, for further details see p. ii.

* ARC Centre of Excellence for Geotechnical Science and Engineering, The University of Newcastle, Newcastle, NSW, Australia. performed on tube specimens retrieved using a fixed-piston sampler $\left(D_{\mathrm{e}}=89 \mathrm{~mm}\right)$. The detailed index characterisation has been combined with one-dimensional and stress-path testing to evaluate compressibility, stiffness, permeability and strength parameters. The main features of the soil response are described and discussed below. A detailed in situ characterisation study will be described in a companion paper where laboratory and in situ data are correlated, aimed at developing a robust geotechnical model for Ballina clay. This paper provides a detailed geotechnical database which adds new experimental evidence about the mechanical behaviour of these complex natural estuarine clays, which are also predominant worldwide.

\section{DESCRIPTION OF THE CHARACTERISATION STUDY}

The characterisation study described here is based on laboratory tests performed at the University of Newcastle (Australia) on tube specimens obtained at the NFTF from two continuous boreholes (Inclo 2 and Mex 9) drilled up to $13 \mathrm{~m}$ depth using an Osterberg-type fixed-piston sampler ( $89 \mathrm{~mm}$ in external diameter). Fig. 1(a) shows the layout of the NFTF facility at the Ballina site (NSW), and includes the location of two embankments recently constructed as part of the ongoing study on soft soil behaviour. Information about the in situ stress state at the Ballina site is summarised in Fig. 1(b). Vertical total stresses were estimated from laboratory measures of natural density (Fig. 3). The profile of $K_{0}$ was interpreted from seismic dilatometer tests (SDMTs) and cone penetration testing with pore pressure measurement (CPTu tests). A relationship between $K_{\mathrm{D}}$ and $K_{0}$ recently proposed by Kouretzis et al. (2015) was used to interpret the results from the SDMT tests. The correlation between CPTu data and friction angle obtained from $\mathrm{CK}_{0} \mathrm{U}$ triaxial tests (Mayne, 2007) was used to estimate values of $K_{0}$ according to: $K_{0}=\left(1-\sin \phi^{\prime}\right) \mathrm{OCR}^{\left(\sin \phi^{\prime}\right)}$ (where 


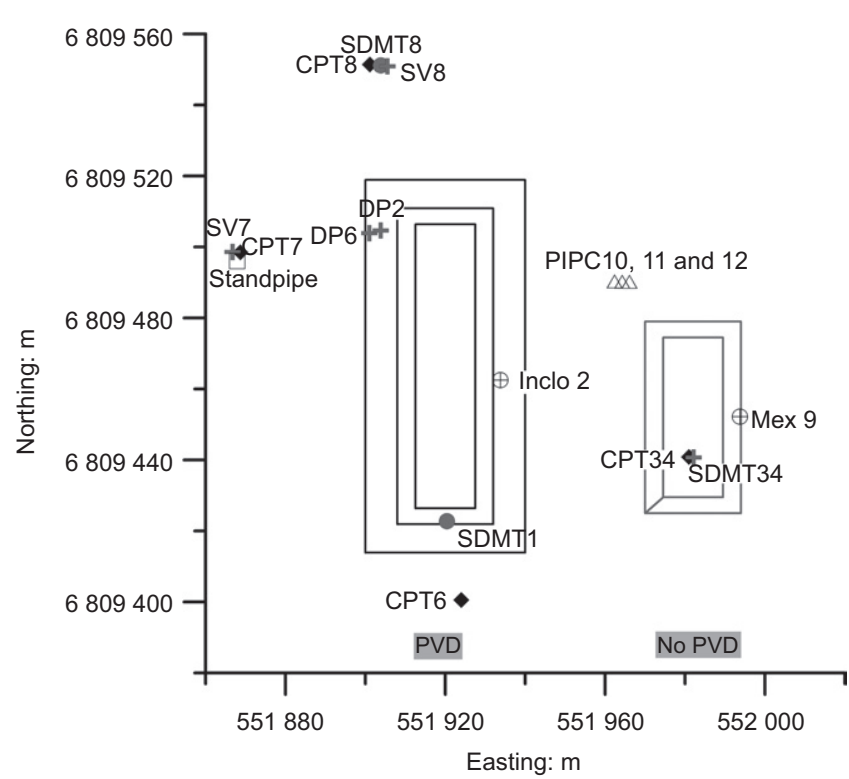

(a)

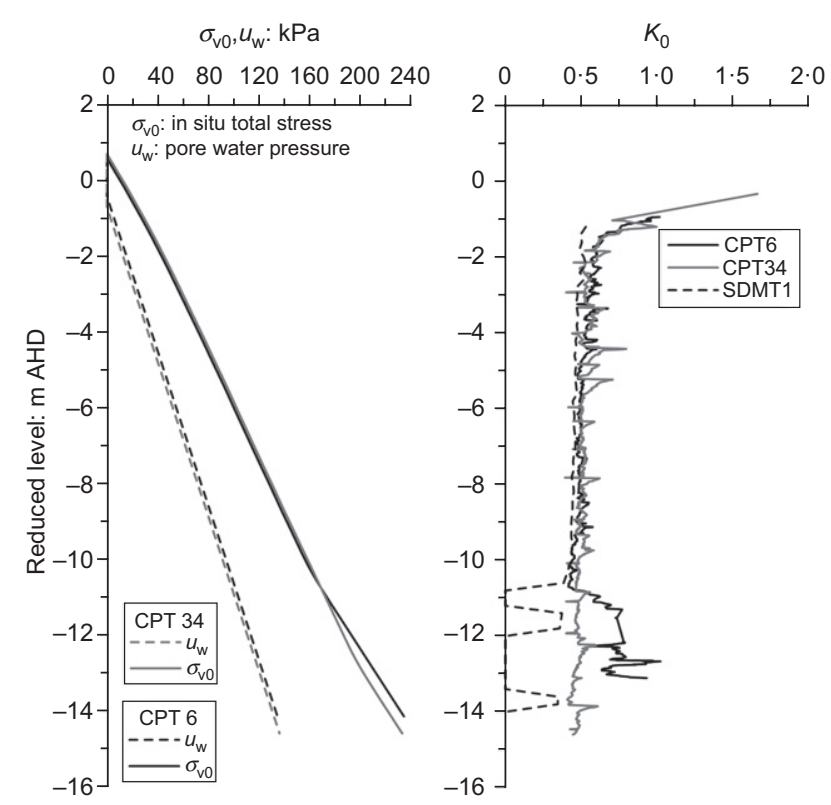

(b)

Fig. 1. NFTF at the Ballina site: (a) plan view; (b) in situ stresses and $K_{0}$

OCR is the overconsolidation ratio). Further details will be given in the companion paper. The two boreholes used in this study refer to two sampling campaigns carried out at the Ballina site in July 2013 and April 2014. The boreholes were drilled for installation of instrumentation used for monitoring the performance of the two embankments. Borehole Inclo 2 was devoted to obtaining profiles of the index and mechanical properties of the soil with depth. The second borehole, Mex 9, located around $50 \mathrm{~m}$ away from borehole Inclo 2, was used to evaluate the variability of the soil properties. The boreholes were drilled using track-mounted rigs. Stainless steel sampling tubes of $600 \mathrm{~mm}$ sample length, wall thickness $t=1.85 \mathrm{~mm}$, no inside clearance and $10^{\circ}$ angle of the cutting edge were employed. They have a ratio $D_{\mathrm{e}} /$ $t=48$, in agreement with suggestions given by Ladd \& DeGroot (2003). After retrieving the sampler, the tube ends were properly sealed in situ with several layers of plastic film underlying a $10 \mathrm{~mm}$-thick polystyrene plate covered externally with wax ( $\approx 15 \mathrm{~mm}$ thickness). This plate was intended to isolate the clay from the thermal gradient caused by waxing. Silicone grease was applied at the interfaces between the tube sampler and the polystyrene to improve the seal. The tube ends were finally covered with plastic lids prior to packing for transport. The specimens were placed, vertically aligned, in sealed plastic containers on a $150 \mathrm{~mm}$-thick layer of wet sand in order to maintain a high-relative-humidity environment $(\mathrm{RH} \approx 99 \%)$ and minimise the moisture losses. The tubes were packed using scraps of polystyrene to induce lateral confinement and absorb the vibrations caused by transport. Finally, the plastic containers were stored in an industrial fridge under constant temperature conditions $\left(T=16^{\circ} \mathrm{C}\right)$ prior to testing.

The characterisation study included: $(a)$ the inspection of tube specimens by using non-destructive image techniques; (b) index characterisation testing; and (c) advanced characterisation testing. Computed axial tomography (CAT) analysis was used to assess (qualitatively) the quality of the tube specimens. The basic characterisation tests focused on determining the index properties, the soil composition and the basic soil parameters in the natural state. Finally, advanced characterisation tests were carried out to determine the variation of the hydraulic and mechanical properties along the soil profile. The key laboratory results are discussed below.

\section{GEOLOGICAL SETTING}

The geological profile at the Ballina site corresponds to the infilling materials of the Richmond River valley in northern NSW, particularly estuarine Quaternary sediments. Based on sediment facies changes and considering zones of oxidation and indurated clay, Bishop (2004) defined three stages of Quaternary deposition for the soils in the area. Stage 1 corresponds to deeper deposits of dense, heavily altered fluvial sandy gravels (South Casino Gravel) accompanied by very stiff clays heavily oxidised and eroded (Dungarubba Clay). Stage 2 and 3 are mainly composed of gravels and sandy clays (lower levels), combined with grey shelly muds which are dominant along the strata. Clays from the lower levels refer to the Gundarimba Clay. The upper estuarine clays, including Ballina soft soils, form the Pimlico Clay unit, which displays variable thickness from $10 \mathrm{~m}$ to $40 \mathrm{~m}$. South Casino Gravel, Dungarubba Clay and Gundarimba Clay are dated to be of Pleistocene age, whereas the deposition of the Pimlico Clay is related to Holocene age (Bishop, 2004; based on Drury, 1982). Within the Pimlico Clay deposit, Bishop (2004) inferred that the absence of sands above reduced level, RL $-10 \mathrm{~m}$ AHD (Australian height datum) corresponds with the formation of a coastal barrier that created a low-energy estuarine deposition environment behind it. Based on oedometer test results, Bishop \& Fityus (2006) observed that the clays above $4 \mathrm{~m}$ depth are structured as they were deposited in a tidal flat environment where a stable structure evolved. Clays below $4 \mathrm{~m}$ depth were considered to be deposited in the less dynamic deeper water environment, which allowed an open structure to be formed.

\section{VISUAL INSPECTION OF TUBE SPECIMENS AND SELECTION OF SOIL SAMPLES FOR LABORATORY TESTING}

One of the challenges when studying the mechanical behaviour of natural soft clays lies in the selection of 'representative' soil specimens for laboratory testing. CAT analysis was performed as a simple and cost-effective tool for assessing sample quality and selecting the best zones to trim specimens for laboratory testing. In particular, this technique was useful for detecting the presence of shells or inclusions as 
well as fissures and cavities. CAT analysis was carried out in collaboration with the radiology section of the Mater hospital in Newcastle (NSW) using a computed tomography (CT) scanner (Toshiba Aquilion) with $135 \mathrm{keV}$ maximum energy. Cross-section images spaced at $2 \mathrm{~mm}$ were taken for three-dimensional reconstruction. Image post processing used the free software Gimias (Gimias, 2011).

Figure 2(a) shows the vertical sections of tube specimens from borehole Inclo 2. There, the attenuation scale varies from white (maximum attenuation or high material density) to black (minimum attenuation or low density). Variations in the grey scale and soil heterogeneities defined by black holes and cracks are observed in the upper $2 \mathrm{~m}$ of the soil profile. Between $2.1 \mathrm{~m}$ and $3.3 \mathrm{~m}$, the soil profile seems homogeneous, while the presence of shells with different sizes (white inclusions) is evident between $3.3 \mathrm{~m}$ and $4.5 \mathrm{~m}$. Few inclusions and shells are observed between $4.5 \mathrm{~m}$ and $5.7 \mathrm{~m}$ depth. The change in grey scale detected around $8.5 \mathrm{~m}$ suggests variations in the soil which are also observed below $11 \cdot 1 \mathrm{~m}$. Cross-section images obtained at four levels for six representative tube specimens are shown in Fig. 2(b) to complement the information from the vertical sections. There, the capital letters F, C and S stand, respectively, for fissure/heterogeneity, cavity/channel and shell. Black holes and cracks observed in the shallow tubes correspond to cavities created by roots and small fissures, respectively. The presence of shells between $3.3 \mathrm{~m}$ and $4.5 \mathrm{~m}$ made it difficult to obtain specimens for the mechanical tests. Vertical cracks, as well as density changes, are identified between $8.1 \mathrm{~m}$ and $8.7 \mathrm{~m}$, whereas cavities and a few shells are observed below $11 \cdot 1 \mathrm{~m}$. Fig. 2(c) shows the vertical sections for the tubes from borehole Mex 9. The comparison between the CAT images clearly shows the soil spatial variability at shallow depths. The 'shelly' zone described above appears in this case at $3.80 \mathrm{~m}$ depth, around $0.30 \mathrm{~m}$ deeper than in borehole Inclo 2. Variations in soil density that are observed around $8.5 \mathrm{~m}$ (Inclo 2) are detected in borehole Mex 9 at $9.6 \mathrm{~m}$. This indicates that the soil profile at the Ballina site seems to follow a sub-horizontal direction. This feature was corroborated from geophysical data obtained at the Ballina site as will be discussed in the companion paper.

The selection of soil samples for mechanical testing was based on the following criteria. For each tube, top and bottom ends $(\approx 1.5$ times the sampler diameter) were used for characterisation tests exclusively, as suggested by Ladd \& DeGroot (2003). Based on the CAT images, the triaxial and oedometer samples were located along the tubes taking into consideration the location of shells, cracks or inclusions. Each tube was cut into slices of variable thickness, depending on the required test, in order to minimise the adhesion force at the clay-tube interface during soil extrusion. Where possible, two triaxial specimens and at least two oedometer specimens per tube were tested.

\section{SOIL STATE AND SOIL COMPOSITION}

Natural water content, dry density and Atterberg limits

Figures 3(a) and 3(b) show the variation of the natural water content, $w_{\text {nat }}$, and dry density, $\rho_{\mathrm{d}}$, with depth down the soil profile. Values of $w_{\text {nat }}$ and $\rho_{\mathrm{d}}$ were estimated from the specimens used for triaxial and oedometer testing. A similar trend is observed between boreholes, although slightly larger values are observed in borehole Mex 9 (around 10\%). The natural water content increases with depth from $20 \%$ $(z \approx 1 \mathrm{~m})$ up to $120 \%$ for specimens below $7 \mathrm{~m}$. Values of liquid limit (LL) $\left(30^{\circ}\right.$ fall cone tests) and plastic limit (PL) (thread-rolling method) are included in Fig. 3(a). Synthetic pore fluid prepared at the same salinity as the natural soil was used in the fall cone and PL tests. Owing to the strong

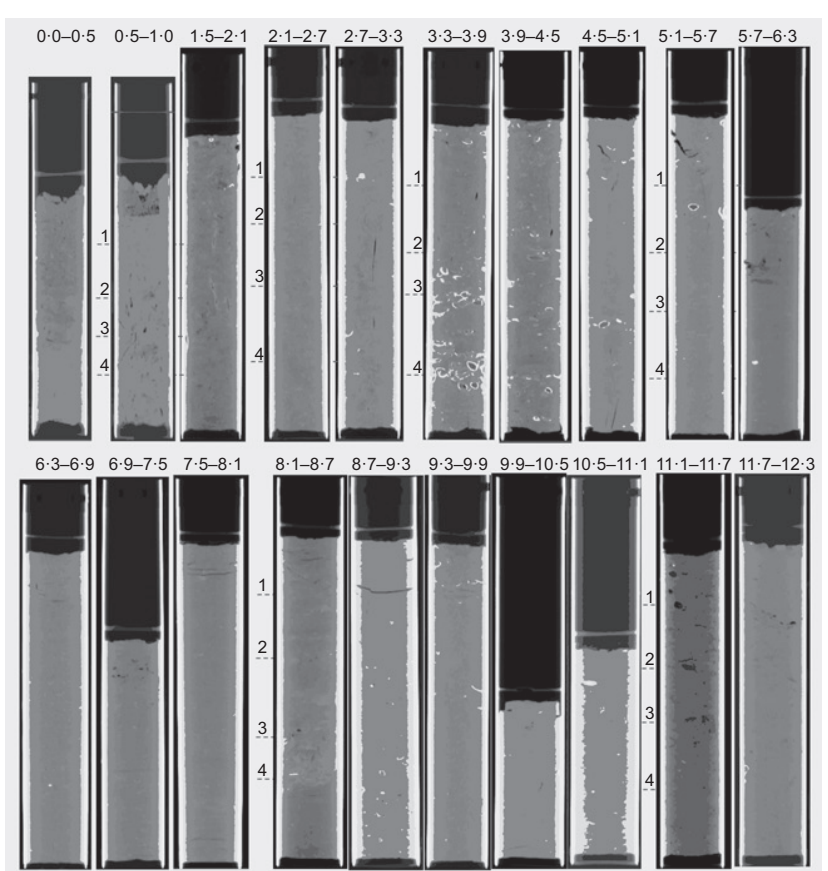

(a)

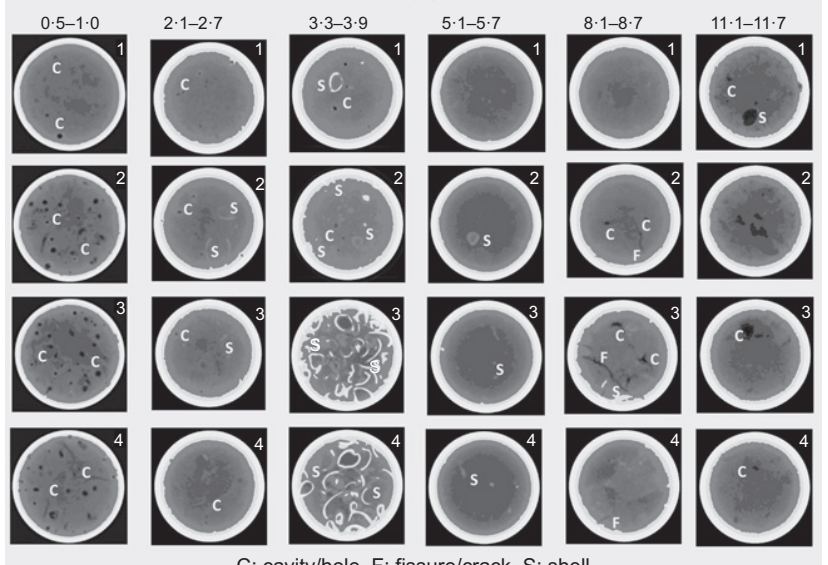

C: cavity/hole, F: fissure/crack, S: shell

(b)

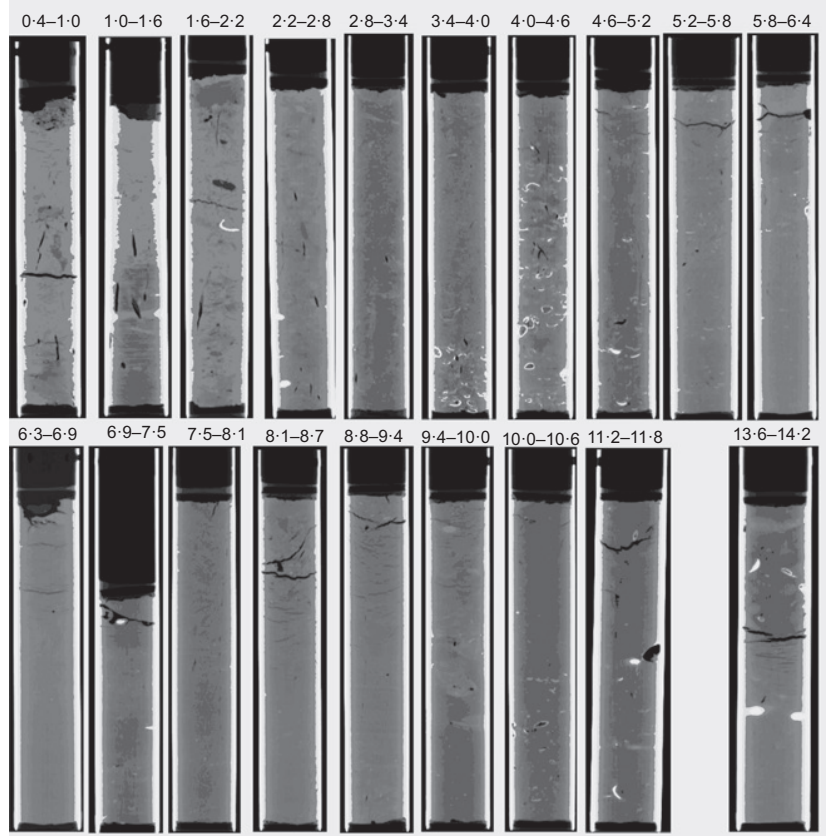

(c)

Fig. 2. CAT scans of tube specimens: (a) vertical sections borehole Inclo 2; (b) cross-sections borehole Inclo 2; (c) vertical sections borehole Mex 9 


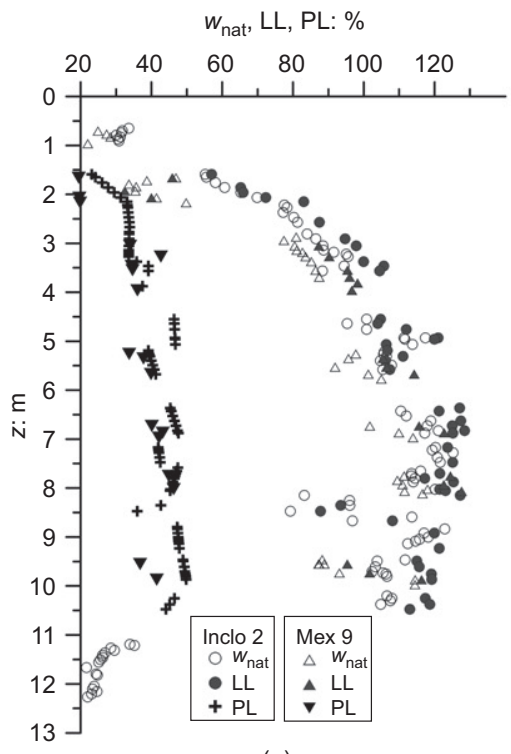

(a)

EC: $\mathrm{mS} / \mathrm{cm}$

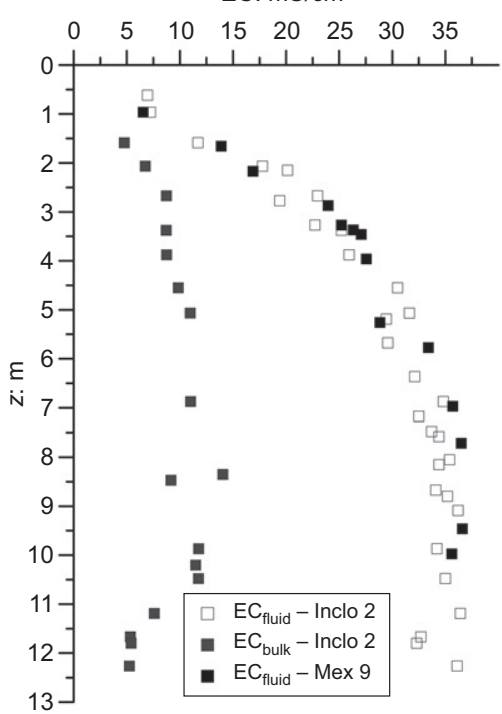

(d)

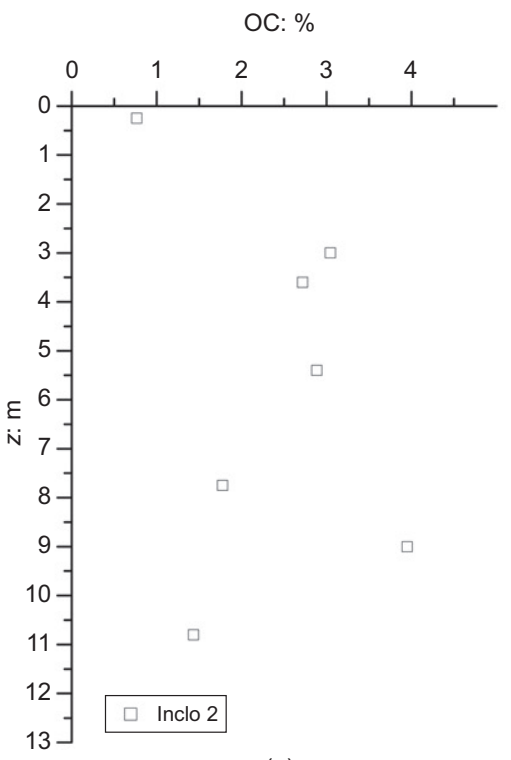

(g)

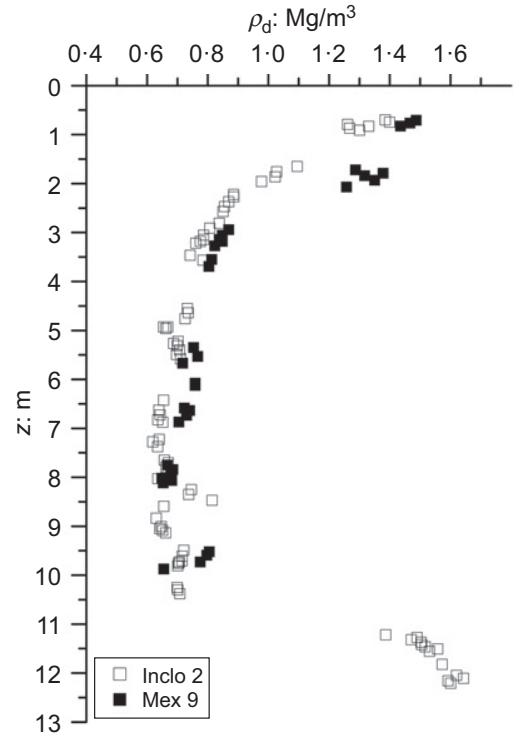

(b)

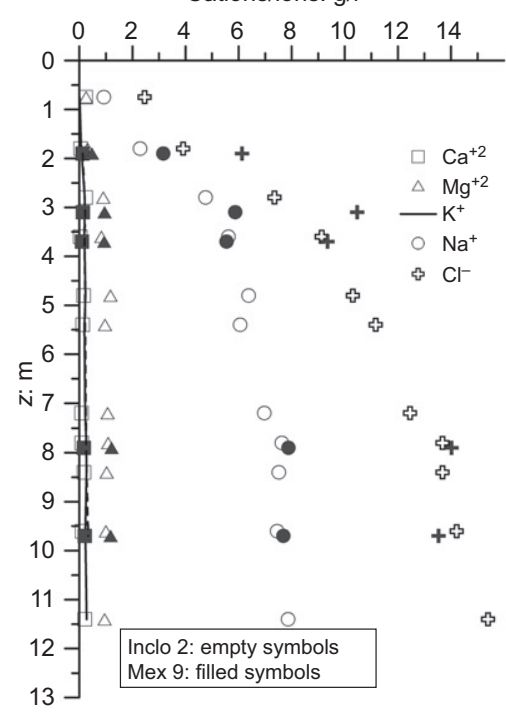

(e)

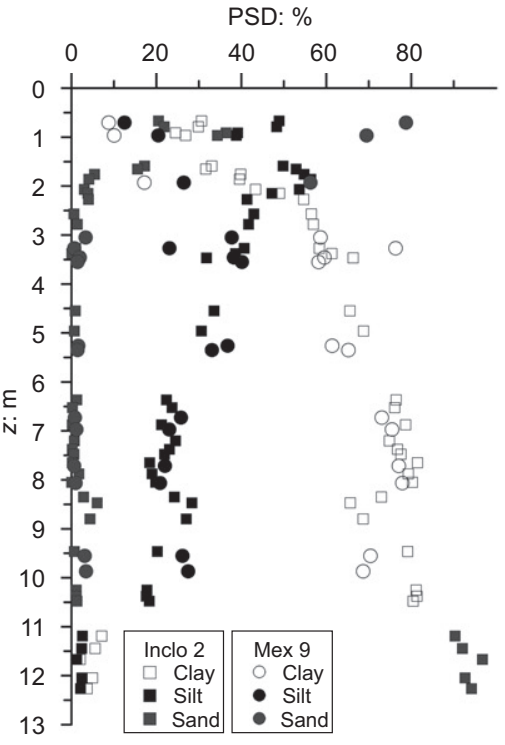

(c)

XRD analysis: \%

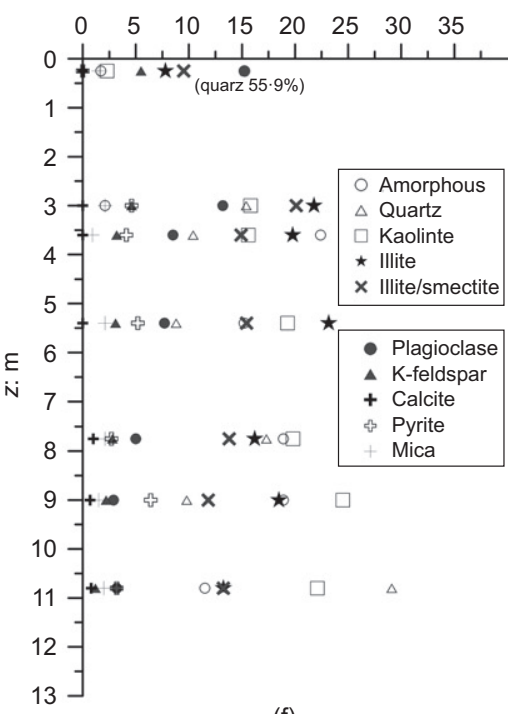

(f)

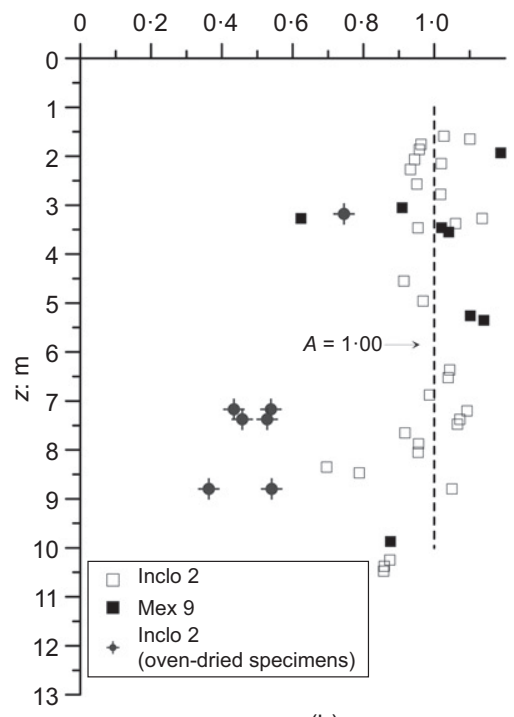

(h)

$\rho_{\text {solids }}: \mathrm{Mg} / \mathrm{m}^{3}$

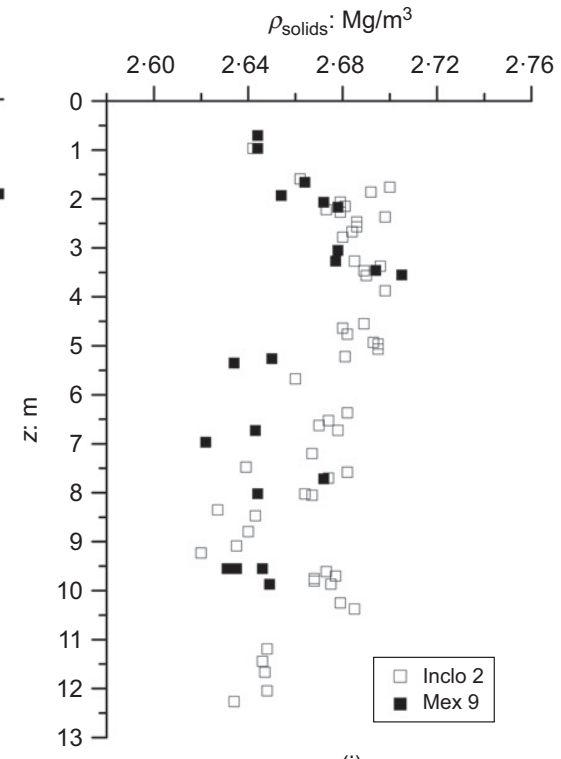

(i)

Fig. 3. Variation of index properties with depth: (a) natural water content, LL and PL; (b) dry density; (c) particle size distributions; (d) electrical conductivity; (e) cations/ions; (f) mineralogical composition; (g) organic content; (h) activity (i) density of solid particles 
influence of drying prior to testing on the LL in Ballina clay (Kelly et al., 2013), soil drying was not allowed. Therefore, the first measurement was carried out at the natural water content and then synthetic pore water was added to the soil mass to increase its moisture content. There is a small difference $(10-15 \%)$ between the natural water content and LL. The PL ranges between $20 \%$ and $53 \%$, whereas values of LL up to $135 \%$ are observed. The dry density reduces from $1.50 \mathrm{Mg} / \mathrm{m}^{3}$ to $0.70 \mathrm{Mg} / \mathrm{m}^{3}$ at $3 \mathrm{~m}$ depth. The minimum variation in $\rho_{\mathrm{d}}$ is observed between $3 \mathrm{~m}$ and $11 \mathrm{~m}$, whereas the increase in $\rho_{\mathrm{d}}$ below $11.1 \mathrm{~m}$ is consistent with the variation in soil density observed in Fig. 2. Higher values of $\rho_{\mathrm{d}}$ for borehole Mex 9 are in agreement with the differences in natural water content observed in Fig. 3(a). The differences in water content between the boreholes are attributed to seasonal variations in the water table level at the time of sampling, as well as additional consolidation of the clay due to the thicker soil profile at borehole Mex 9. Table 1 summarises the results obtained from the characterisation tests for boreholes Inclo 2 and Mex 9.

\section{Particle size distributions}

Figure 3(c) shows the particle size distributions (PSD), obtained using a particle size analyser (Sedigraph III, Micromeritics), for specimens from boreholes Inclo 2 and Mex 9. Clear differences between boreholes are observed at shallow depths $(z<2 \mathrm{~m})$ mainly in terms of sand content. It reduces to $5 \%$ in borehole Inclo 2 and remains around 55\% in borehole Mex 9. Clay content is predominant underneath $2 \mathrm{~m}$ with maximum values up to $82 \%$ (where the sand content lies around 1\%). The important increase in sand content observed below $11 \cdot 1 \mathrm{~m}$ confirms the change in soil composition shown in Fig. 2.

\section{Pore water salinity}

The presence of salts in the pore fluid of marine clays is an important aspect to be evaluated as it may affect the index and mechanical properties of the soil. As discussed by Pineda et al. (2013), the modification of the pore fluid salinity in Ballina clay leads to important variations of the drained shear strength parameters $\left(c^{\prime}\right.$ and $\left.\phi^{\prime}\right)$. They reported a reduction in $\phi^{\prime}$ of around $5^{\circ}$ when deionised water was used in direct shear tests. The implications of such a variation in geotechnical design are not negligible and emphasise the need for assessing and controlling the pore water salinity during mechanical tests. The salinity of the bulk material (fluid + solids) and the pore fluid was evaluated from electrical conductivity (EC) measurements. Bulk measurements were estimated by inserting an EC probe into the soil mass. This soil was then compressed, under a very slow, strain-controlled mode, to squeeze out the $15 \mathrm{~cm}^{3}$ of pore fluid required to estimate $\mathrm{EC}_{\text {fluid. }}$. Four measurements per tube were obtained by using the soil from the top and bottom ends. The variation of $\mathrm{EC}_{\text {bulk }}$ and $\mathrm{EC}_{\text {fluid }}$ with depth is shown in Fig. 3(d), where a similar trend is observed between boreholes. The bulk measurements vary with depth from $4 \mathrm{mS} / \mathrm{cm}$ to $15 \mathrm{mS} / \mathrm{cm}$. The reduction in $\mathrm{EC}_{\text {bulk }}$ at $11 \cdot 1 \mathrm{~m}$ depth confirms the change in soil composition discussed above. The values of $\mathrm{EC}_{\text {fluid }}$ are larger than $\mathrm{EC}_{\text {bulk }}$, and varied from $7 \mathrm{mS} / \mathrm{cm}$ up to $36 \mathrm{mS} / \mathrm{cm}$ (the average below $5 \mathrm{~m}$ ). The lower values measured at shallow depths may be due to dilution by fresh water from the ground surface. The measured $\mathrm{EC}_{\text {fluid }}$ corresponds to concentrations of sodium chloride $(\mathrm{NaCl})$ between 4 and $24 \mathrm{~g} / \mathrm{l}$ in deionised water (the concentration of the seawater is $35 \mathrm{~g} / \mathrm{l}$ ). Based on the variation of $\mathrm{EC}_{\text {fluid, }}$, synthetic pore fluid was prepared and used in the mechanical (triaxial and oedometer) and index (Atterberg limits) tests.

\section{Pore water chemistry}

The chemistry of the pore water was evaluated from groundwater analyses performed on the water squeezed from the soil that was used previously for the estimation of $\mathrm{EC}_{\text {fluid }}$. The test procedure followed the suggested method by APHA (2012). Fig. 3(e) shows the variation of the predominant cations and anions in specimens from boreholes Inclo 2 and Mex 9. The most abundant cations and anions are sodium $(0 \cdot 93-8.23 \mathrm{~g} / \mathrm{l})$ and chloride $(2 \cdot 5-15 \cdot 4 \mathrm{~g} / \mathrm{l})$, respectively. Additional relevant cations are magnesium and calcium $(<1 \mathrm{~g} / \mathrm{l})$. The total alkalinity of the pore water (concentration of bicarbonates) ranges between 0.6 and $2.2 \mathrm{~g} / 1$ of calcium carbonate $\left(\mathrm{CaCO}_{3}\right)$. The larger concentration of sodium and chloride reported in Fig. 3(e) supports the use of synthetic pore fluid during mechanical tests.

\section{Mineralogy}

Quantitative X-ray diffraction (XRD) analyses were performed on specimens from borehole Inclo 2. A key aspect in the mineralogical characterisation of natural estuarine clays is the proper separation between mineral phases, in particular illite and interstratified illite/smectite (illite-bearing smectite) fractions. Here, the approach described by Moore \& Reynolds (1997) was followed. The XRD results reported in Fig. 3(f) show that the mineralogical composition of Ballina clay varies down the soil profile with the quartz fraction having the principal variation. The specimens are composed of: amorphous minerals $(1 \cdot 7-22 \cdot 4 \%)$, kaolinite $(2 \cdot 3-24 \cdot 5 \%)$, illite $(7 \cdot 8-23 \cdot 3 \%)$, quartz $(8 \cdot 8-55 \cdot 9 \%)$, interstratified illite/smectite $(9 \cdot 5-20 \cdot 1 \%)$, plagioclase $(2 \cdot 9-15 \cdot 2 \%)$, pyrite $(0-6 \cdot 4 \%)$, K-feldspar $(1 \cdot 2-5 \cdot 5 \%)$, mica $(0 \cdot 9-2 \cdot 1 \%)$ and calcite $(0-1 \cdot 0 \%)$.

\section{Organic content}

The loss of ignition method was used to determine the organic content (OC) of the specimens from borehole Inclo 2 (see Fig. 3(g)). The OC lies between 0.8 and $4 \%$, although an average value of $3 \%$ may be defined for soils between 3 and $9 \mathrm{~m}$. The presence of organics within the natural clay emphasises the necessity for a proper sealing method for both the tube and block samples in order to minimise the activation of biological processes (e.g. oxidation) before testing. This aspect was considered during the sampling campaign at the Ballina site, as in the earlier section entitled 'Geological setting'.

\section{Soil activity}

Values of soil activity are shown in Fig. 3(h). An average value of 1 (dotted line) can be adopted for Ballina clay, despite the scatter observed in the specimens from borehole Mex 9. According to the classification proposed by Skempton (1953), Ballina clay lies within the group of normal clays $(0 \cdot 75<A<1 \cdot 25)$, which is in agreement with the activity of their dominant clay minerals (illite and kaolinite). As will be described below, the reduction in LL (and plasticity index (PI)) caused by previous soil drying has an impact on soil activity. It reduces to half for specimens dried prior to the fall cone tests (see Fig. 3(h)). Such a dependency may lead to misleading use of available empirical relationships between activity and soil parameters.

\section{Density of solid particles}

Gas pycnometer tests were carried out to estimate the density of the solid particles, $\rho_{\text {solids. }}$. The values of $\rho_{\text {solids }}$ reported in Fig. 3(i) correspond to the average of ten 
readings. In general, $\rho_{\text {solids }}$ lies between 2.64 and $2.68 \mathrm{Mg} / \mathrm{m}^{3}$. Similar results are observed between boreholes except for specimens located between 4 and $7 \mathrm{~m}$. Lower values were estimated for borehole Mex 9 .

\section{Soil plasticity}

Figure 4 shows Casagrande's plasticity chart for specimens from boreholes Inclo 2 and Mex 9. For simplicity, test results have been plotted using the tube provenance. All specimens lie close to the A-line. Most of the tested soils classify as clays of intermediate to extremely high plasticity, and there is a consistent increase in soil plasticity with depth in both boreholes. The chief difference between boreholes is observed at shallow depths and is mainly due to the low clay content observed in borehole Mex 9. These soils classify as clays of intermediate to high plasticity. The soils located below $2.7 \mathrm{~m}$ classify as clays (a few as silts) of extremely high plasticity. The highest plasticity is observed for specimens located between $6.3 \mathrm{~m}$ and $7.5 \mathrm{~m}$ with values of PI and LL around $80 \%$ and $130 \%$, respectively.

It has been recognised in other soft clays (e.g. Hight et al., 1992) that the occurrence of organics causes an important variation in soil plasticity after soil drying. Additional tests were performed to evaluate this dependency in Ballina clay. Various test results are enclosed by a dotted ellipse in Fig. 4. These specimens were oven dried at $105^{\circ}$ for 2 days before testing and fall cone tests were carried out using either distilled water or synthetic pore fluid (at the same salinity as the natural soil). Previous oven drying causes a strong reduction in the LL $(20-45 \%)$, whereas variation in the PL was less significant. The reduction in the LL led to those soils being classified as silts of high plasticity. The pore fluid used during the fall cone tests also influences the measured LL values, with the reduction in the LL due to previous oven drying being less pronounced if deionised water is employed. Differences in the LL when using deionised water or synthetic pore fluid are in the range $8-13 \%$. The results described above highlight the importance of proper standards for determining index properties in soft clays with a small amount of organics. In particular, the aforementioned dependencies must be considered when adopting empirical correlations, such as those relating $I_{\mathrm{P}}$ with $\phi^{\prime}, K_{0}, s_{\mathrm{u}}, C_{\mathrm{c}}$, among others (e.g. Skempton, 1954; Mitchell, 1976; Leroueil et al., 1983; Carrier \& Beckman, 1984, 1985), that are widely used in geotechnical practice.

\section{SAMPLE DISTURBANCE}

The ultimate goal of the geotechnical characterisation is to obtain index and mechanical properties which are representative of the in situ conditions to be used in geotechnical design. When mechanical properties are obtained from laboratory tests, the quality of the specimens plays a dominant role in the representativeness of the soil parameters. The sample quality of the tube specimens has been assessed using the suggestions proposed by Lunne et al. (1997). This is based on normalising the change in void ratio, $\Delta e / e_{0}$, that is required to recompress the specimen to the in situ stress conditions. Fig. 5(a) shows the results of 55 mechanical tests (sandy specimens are not considered here), including constant rate of strain tests and triaxial tests. In this figure, 51 out of 55 specimens have a yield stress ratio (YSR $=\sigma_{\text {yield }}^{\prime} / \sigma_{\mathrm{v} 0}^{\prime}$, where $\sigma_{\text {yield }}^{\prime}$ is the yield stress and $\sigma_{\mathrm{v} 0}^{\prime}$ is the in situ vertical effective stress) below 2 , with four between 2 and 3. According to this approach, most of the specimens (47) are of very good to excellent quality, eight specimens are of good to fair quality, and only three are of poor quality (Tables 2 and 4). Fig. 5 shows that most of the lower quality samples correspond to triaxial specimens from borehole Mex 9.

Figure 5(b) shows the assessment of the sample quality for specimens subjected to CRS tests (see below) in which the shear wave velocity at in situ stress, $V_{\mathrm{s}(\mathrm{BE}) \sigma^{\prime} \mathrm{v} 0}$, was determined using bender element transducers. The shear wave velocity has been normalised in Fig. 5(b) using the corresponding values obtained from SDMT tests (a detailed analysis of the SDMT data will be given in the companion paper). Values of $V_{\mathrm{s}}$ from boreholes Inclo 2 and Mex 9 were normalised against results from SDMT1 and SDMT34, respectively (see Fig. 1). They are plotted against the normalised void ratio, $\Delta e / e_{0}$ in Fig. 5(b). There is a consistent relationship between the normalised shear wave velocity at in situ stress and the sample quality. Values of the ratio $V_{\mathrm{s}(\mathrm{BE}) \sigma^{\prime} \mathrm{v} 0} / V_{\mathrm{s}(\mathrm{SDMT})}$ range from 0.85 to $1.02(0.96$ on average) for specimens rated as good to excellent quality. Two additional specimens show values around $1 \cdot 13$, but these correspond to shallow samples with a sand content higher than $10 \%$. For the specimens

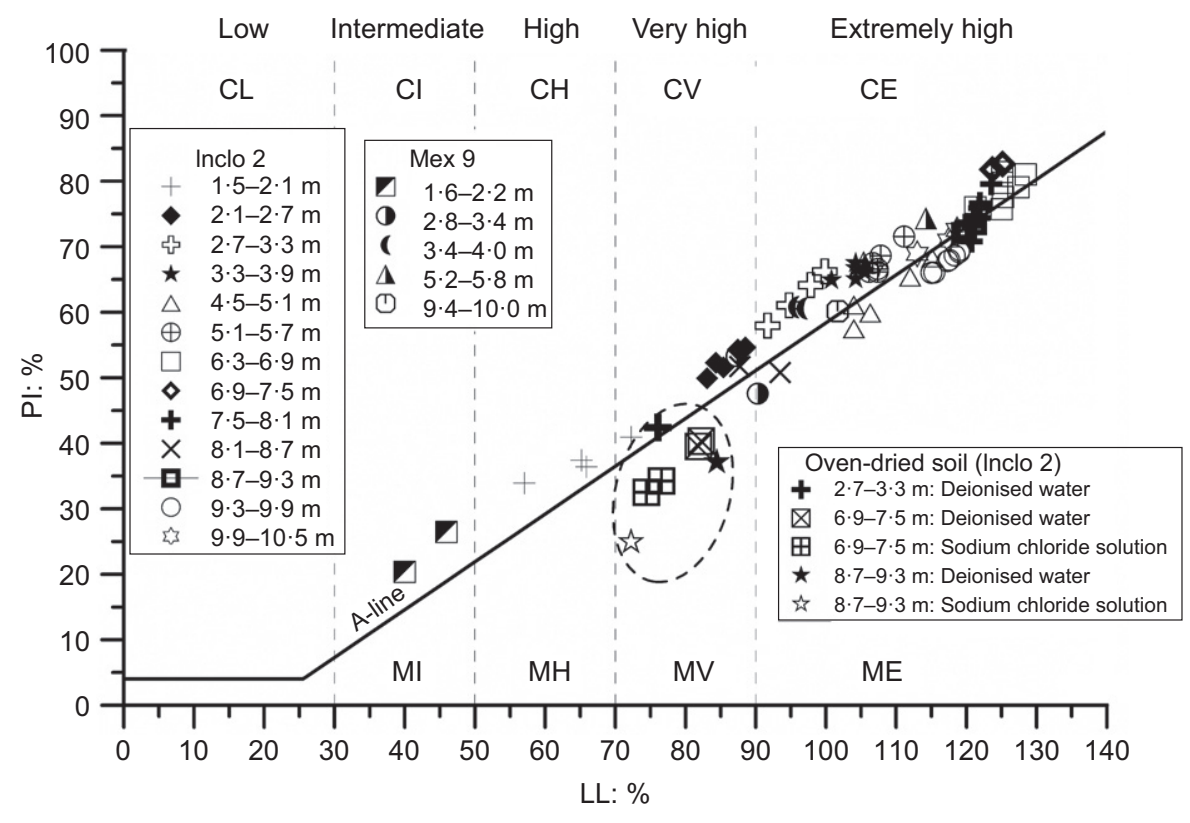

Fig. 4. Soil plasticity of tested specimens 
Table 1. Index properties for boreholes Inclo 2 and Mex 9

\begin{tabular}{|c|c|c|c|c|c|c|c|c|c|c|}
\hline $\begin{array}{l}\text { Tube } \\
\text { depth: m }\end{array}$ & $w_{\text {nat }}: \%$ & LL: \% & PL: \% & $\rho_{\mathrm{d}}: \mathrm{Mg} / \mathrm{m}^{3}$ & $\%<2 \mu \mathrm{m}: \%$ & $\begin{array}{l}\mathrm{EC}_{\text {bulk: }} \text { : } \\
\mathrm{mS} / \mathrm{cm}\end{array}$ & $\begin{array}{l}\mathrm{EC}_{\text {fluid: }} \text { : } \\
\mathrm{mS} / \mathrm{cm}\end{array}$ & $\begin{array}{l}\rho_{\text {solids }} \\
\mathrm{Mg} / \mathrm{m}^{3}\end{array}$ & OC: $\%$ & $A$ \\
\hline \multicolumn{11}{|c|}{ Borehole Inclo 2} \\
\hline \multirow[t]{2}{*}{$0 \cdot 5-1 \cdot 0$} & $30 \cdot 1$ & - & - & $1 \cdot 27$ & $24 \cdot 5$ & - & $6 \cdot 95$ & $2 \cdot 58$ & $0 \cdot 8$ & - \\
\hline & $33 \cdot 6(31 \cdot 4)$ & & & 1.40 & $30 \cdot 6$ & & $7 \cdot 21$ & $2 \cdot 64$ & & \\
\hline \multirow[t]{2}{*}{$1 \cdot 5-2 \cdot 1$} & $55 \cdot 2$ & $57 \cdot 0$ & $23 \cdot 12$ & 0.98 & $31 \cdot 6$ & $4 \cdot 76$ & $11 \cdot 7$ & $2 \cdot 66$ & - & $0 \cdot 94$ \\
\hline & $69 \cdot 9(60 \cdot 8)$ & $72 \cdot 30$ & $31 \cdot 31$ & $1 \cdot 70$ & $43 \cdot 4$ & 6.73 & $17 \cdot 8$ & $2 \cdot 70$ & & $1 \cdot 10$ \\
\hline \multirow[t]{2}{*}{$2 \cdot 1-2 \cdot 7$} & $77 \cdot 30$ & $83 \cdot 10$ & $32 \cdot 1$ & $0 \cdot 85$ & $49 \cdot 0$ & $8 \cdot 73$ & $20 \cdot 15$ & $2 \cdot 67$ & - & $0 \cdot 93$ \\
\hline & $81.30(78.93)$ & $87 \cdot 45$ & $33 \cdot 9$ & 0.89 & $56 \cdot 5$ & & $23 \cdot 0$ & $2 \cdot 70$ & & $1 \cdot 02$ \\
\hline \multirow[t]{2}{*}{$2 \cdot 7-3 \cdot 3$} & $84 \cdot 0$ & $94 \cdot 7$ & $33 \cdot 65$ & $0 \cdot 76$ & $56 \cdot 9$ & - & $19 \cdot 4$ & $2 \cdot 68$ & $3 \cdot 0$ & $1 \cdot 02$ \\
\hline & $95 \cdot 6(90 \cdot 0)$ & $97 \cdot 8$ & & $0 \cdot 84$ & $58 \cdot 3$ & & $22 \cdot 72$ & & & $1 \cdot 14$ \\
\hline \multirow[t]{2}{*}{$3 \cdot 3-3 \cdot 9$} & $88 \cdot 3$ & $99 \cdot 9$ & $35 \cdot 9$ & $0 \cdot 74$ & $61 \cdot 3$ & $8 \cdot 7$ & $25 \cdot 22$ & $2 \cdot 69$ & $2 \cdot 7$ & $0 \cdot 95$ \\
\hline & $94 \cdot 5(91 \cdot 60)$ & $105 \cdot 7$ & $37 \cdot 5$ & $0 \cdot 78$ & $66 \cdot 3$ & 8.75 & $25 \cdot 93$ & & & 1.06 \\
\hline \multirow[t]{2}{*}{$4 \cdot 5-5 \cdot 1$} & $100 \cdot 8$ & $104 \cdot 0$ & $46 \cdot 4$ & 0.65 & $62 \cdot 7$ & $9 \cdot 84$ & $30 \cdot 5$ & $2 \cdot 69$ & - & $0 \cdot 91$ \\
\hline & $117 \cdot 4(107 \cdot 3)$ & $121 \cdot 0$ & $46 \cdot 8$ & 0.74 & $68 \cdot 8$ & $11 \cdot 0$ & $31 \cdot 6$ & & & 1.07 \\
\hline \multirow[t]{2}{*}{$5 \cdot 1-5 \cdot 7$} & $104 \cdot 74$ & $106 \cdot 1$ & $39 \cdot 20$ & $0 \cdot 69$ & - & - & $29 \cdot 44$ & $2 \cdot 66$ & $2 \cdot 9$ & - \\
\hline & $107 \cdot 83(106 \cdot 0)$ & $111 \cdot 1$ & $41 \cdot 20$ & $0 \cdot 71$ & & & $29 \cdot 6$ & $2 \cdot 68$ & & \\
\hline \multirow{2}{*}{$6 \cdot 3-6 \cdot 9$} & $110 \cdot 5$ & $121 \cdot 3$ & $43 \cdot 7$ & $0 \cdot 64$ & $76 \cdot 1$ & $11 \cdot 01$ & $32 \cdot 1$ & $2 \cdot 68$ & - & 0.99 \\
\hline & $121 \cdot 0(116 \cdot 3)$ & $128 \cdot 5$ & $49 \cdot 3$ & $0 \cdot 65$ & $78 \cdot 7$ & & $34 \cdot 8$ & & & $1 \cdot 04$ \\
\hline \multirow[t]{2}{*}{$6 \cdot 9-7 \cdot 5$} & $119 \cdot 40$ & $123 \cdot 7$ & $41 \cdot 9$ & 0.62 & $74 \cdot 9$ & - & $32 \cdot 5$ & $2 \cdot 64$ & - & $1 \cdot 07$ \\
\hline & $126 \cdot 15(122 \cdot 3)$ & $125 \cdot 1$ & $42 \cdot 5$ & $0 \cdot 64$ & $77 \cdot 5$ & & $33 \cdot 7$ & $2 \cdot 68$ & & 1.09 \\
\hline \multirow[t]{2}{*}{$7 \cdot 5-8 \cdot 1$} & $113 \cdot 5$ & $117 \cdot 2$ & $46 \cdot 0$ & $0 \cdot 64$ & $79 \cdot 3$ & - & $34 \cdot 4$ & $2 \cdot 66$ & 1.8 & $0 \cdot 92$ \\
\hline & $120 \cdot 2(115 \cdot 3)$ & $125 \cdot 3$ & $50 \cdot 0$ & $0 \cdot 67$ & $81 \cdot 4$ & & $35 \cdot 4$ & 2.68 & & 0.96 \\
\hline \multirow[t]{2}{*}{$8 \cdot 1-8 \cdot 7$} & $79 \cdot 3$ & $87 \cdot 8$ & $36 \cdot 0$ & 0.66 & $65 \cdot 6$ & $9 \cdot 15$ & $34 \cdot 1$ & $2 \cdot 64$ & - & $0 \cdot 70$ \\
\hline & $113.6(94 \cdot 20)$ & $127 \cdot 3$ & $42 \cdot 7$ & $0 \cdot 81$ & $73 \cdot 0$ & $14 \cdot 04$ & $34 \cdot 4$ & & & 0.79 \\
\hline \multirow[t]{2}{*}{$8 \cdot 7-9 \cdot 3$} & $112 \cdot 43$ & 120 & $47 \cdot 3$ & 0.63 & $68 \cdot 7$ & - & $35 \cdot 2$ & $2 \cdot 62$ & $4 \cdot 0$ & 1.05 \\
\hline & $122 \cdot 9(116 \cdot 8)$ & $121 \cdot 4$ & $47 \cdot 9$ & 0.66 & & & $36 \cdot 2$ & $2 \cdot 64$ & & \\
\hline \multirow{2}{*}{$9 \cdot 3-9 \cdot 9$} & $102 \cdot 4$ & 115 & $48 \cdot 9$ & $0 \cdot 70$ & $79 \cdot 2$ & $11 \cdot 76$ & $34 \cdot 2$ & $2 \cdot 67$ & - & - \\
\hline & $111 \cdot 7(105 \cdot 6)$ & $119 \cdot 2$ & $49 \cdot 8$ & $0 \cdot 72$ & & & & & & \\
\hline \multirow[t]{2}{*}{$9 \cdot 9-10 \cdot 5$} & $104 \cdot 8$ & 113 & $44 \cdot 1$ & $0 \cdot 70$ & $80 \cdot 4$ & $11 \cdot 48$ & $35 \cdot 0$ & $2 \cdot 68$ & $1 \cdot 4$ & $0 \cdot 87$ \\
\hline & $108 \cdot 0(106 \cdot 7)$ & $118 \cdot 7$ & $46 \cdot 5$ & $0 \cdot 71$ & $81 \cdot 3$ & $11 \cdot 75$ & & & & \\
\hline \multirow[t]{2}{*}{$11 \cdot 1-11 \cdot 7$} & $25 \cdot 1$ & - & - & $1 \cdot 39$ & $2 \cdot 0$ & $5 \cdot 33$ & $32 \cdot 7$ & $2 \cdot 65$ & - & - \\
\hline & $33.90(28.60)$ & & & 1.56 & $7 \cdot 1$ & $7 \cdot 58$ & $36 \cdot 4$ & & & \\
\hline \multirow[t]{2}{*}{$11 \cdot 7-12 \cdot 3$} & $22 \cdot 0$ & - & - & $1 \cdot 58$ & $3 \cdot 7$ & $5 \cdot 25$ & $32 \cdot 3$ & $2 \cdot 63$ & - & - \\
\hline & $24 \cdot 75(23 \cdot 72)$ & & & $1 \cdot 64$ & $4 \cdot 9$ & $5 \cdot 4$ & $36 \cdot 1$ & $2 \cdot 65$ & & \\
\hline \multicolumn{11}{|c|}{ Borehole Mex 9} \\
\hline \multirow[t]{2}{*}{$0 \cdot 4-1 \cdot 0$} & $22 \cdot 0$ & - & - & $1 \cdot 44$ & $8 \cdot 8$ & - & $6 \cdot 55$ & $2 \cdot 64$ & - & - \\
\hline & $27 \cdot 40(25 \cdot 70)$ & & & $1 \cdot 49$ & $10 \cdot 1$ & 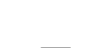 & & & & \\
\hline $1 \cdot 6-2 \cdot 2$ & $36 \cdot 65$ & $\begin{array}{l}32 \cdot 5 \\
46 \cdot 0\end{array}$ & $\begin{array}{l}19 \cdot 5 \\
19 \cdot 8\end{array}$ & $\begin{array}{l}1 \cdot 26 \\
1 \cdot 38\end{array}$ & $17 \cdot 17$ & - & $\begin{array}{l}13 \cdot 9 \\
16 \cdot 9\end{array}$ & $\begin{array}{l}2.65 \\
2.68\end{array}$ & - & $1 \cdot 19$ \\
\hline $2 \cdot 8-3 \cdot 4$ & $77 \cdot 50$ & $87 \cdot 3$ & $34 \cdot 0$ & $0 \cdot 82$ & $58 \cdot 6$ & - & $24 \cdot 0$ & $2 \cdot 68$ & - & $0 \cdot 62$ \\
\hline & $85 \cdot 10(81 \cdot 60)$ & $90 \cdot 3$ & $42 \cdot 7$ & $0 \cdot 87$ & $76 \cdot 3$ & & $26 \cdot 3$ & & & 0.91 \\
\hline $3 \cdot 4-4 \cdot 0$ & $86 \cdot 40$ & $95 \cdot 4$ & $34 \cdot 4$ & $0 \cdot 81$ & $58 \cdot 2$ & - & $27 \cdot 1$ & $2 \cdot 69$ & - & $1 \cdot 02$ \\
\hline & $87 \cdot 40(86 \cdot 91)$ & $98 \cdot 3$ & $36 \cdot 1$ & & $59 \cdot 5$ & & $27 \cdot 6$ & $2 \cdot 71$ & & $1 \cdot 04$ \\
\hline $5 \cdot 2-5 \cdot 8$ & $95 \cdot 70$ & $105 \cdot 4$ & $33 \cdot 7$ & $0 \cdot 72$ & $61 \cdot 4$ & - & $28 \cdot 9$ & $2 \cdot 63$ & - & $1 \cdot 10$ \\
\hline & $105 \cdot 0(99 \cdot 93)$ & $114 \cdot 2$ & $39 \cdot 9$ & $0 \cdot 77$ & $65 \cdot 2$ & & $33 \cdot 4$ & $2 \cdot 65$ & & $1 \cdot 14$ \\
\hline $6 \cdot 4-7 \cdot 0$ & $101 \cdot 7$ & $115 \cdot 6$ & $40 \cdot 1$ & $0 \cdot 71$ & $73 \cdot 1$ & - & $35 \cdot 7$ & $2 \cdot 62$ & - & - \\
\hline & $113.9(108 \cdot 5)$ & $122 \cdot 7$ & $43 \cdot 2$ & 0.76 & $75 \cdot 5$ & & & 2.64 & & \\
\hline $7 \cdot 6-8 \cdot 2$ & $109 \cdot 5$ & $112 \cdot 6$ & $44 \cdot 9$ & $0 \cdot 65$ & $77 \cdot 1$ & - & $36 \cdot 5$ & $2 \cdot 64$ & - & - \\
\hline & $116 \cdot 6(113 \cdot 0)$ & $127 \cdot 6$ & $46 \cdot 3$ & $0 \cdot 69$ & $77 \cdot 90$ & & & $2 \cdot 67$ & & \\
\hline $9 \cdot 4-10 \cdot 0$ & $87 \cdot 30$ & $95 \cdot 4$ & $36 \cdot 8$ & $0 \cdot 66$ & $68 \cdot 7$ & - & $35 \cdot 6$ & $2 \cdot 63$ & - & 0.88 \\
\hline & $114 \cdot 5(93 \cdot 24)$ & $116 \cdot 3$ & $41 \cdot 5$ & $0 \cdot 81$ & $70 \cdot 4$ & & $36 \cdot 6$ & $2 \cdot 65$ & & \\
\hline
\end{tabular}

Minimum and maximum values are reported. Mean values in brackets.

rated as poor quality, the normalised shear wave velocity lies around $0 \cdot 75$. In spite of the fact that no standard method is currently available for quantifying the sample disturbance in soft soils, the results presented in Fig. 5 confirm the reliability of the sampling method in obtaining good quality specimens for Ballina clay.

\section{COMPRESSIBILITY}

Constant rate of strain (CRS) oedometer tests were carried out to evaluate the compression parameters for Ballina clay. These included the determination of the yield stress, $\sigma_{\text {yield }}^{\prime}$, the yield stress ratio, YSR, and the compression/swelling indexes, $C_{\mathrm{c}}$ and $C_{\mathrm{s}}$. Additional parameters like the constrained modulus, $M$, the consolidation coefficient, $c_{\mathrm{v}}$, and the water permeability, $k_{\mathrm{w}}$, were also interpreted from the CRS results.
Tests were performed in a stainless steel oedometer cell equipped with bender elements to determine the shear wave velocity, $V_{\mathrm{s}}$. The CRS equipment used a thin stainless steel oedometric ring ( $\phi_{\text {int }}=48 \mathrm{~mm}, h=20 \mathrm{~mm}, t=1 \mathrm{~mm}$, corresponding to an area ratio of $9 \%$ ) to retrieve samples following the experimental procedure described by Pineda et al. (2012). Excess pore-water pressure was measured at the sample base, whereas the top drainage surface was maintained at atmospheric conditions during loading. Synthetic pore fluid with the same salinity as the natural soil was used in the CRS tests, which consisted of three stages: $(a)$ saturation; $(b)$ loading; and $(c)$ unloading. The samples were subjected to a $48 \mathrm{~h}$ saturation stage under constant vertical total stress $\left(\sigma_{\mathrm{v}} \approx 21 \mathrm{kPa}\right)$ and water back-pressure $\left(u_{\mathrm{w}} \approx 10 \mathrm{kPa}\right)$. After that, the specimens were loaded under a constant displacement rate of $0.004 \mathrm{~mm} / \mathrm{min}$, which produced strain rates at 


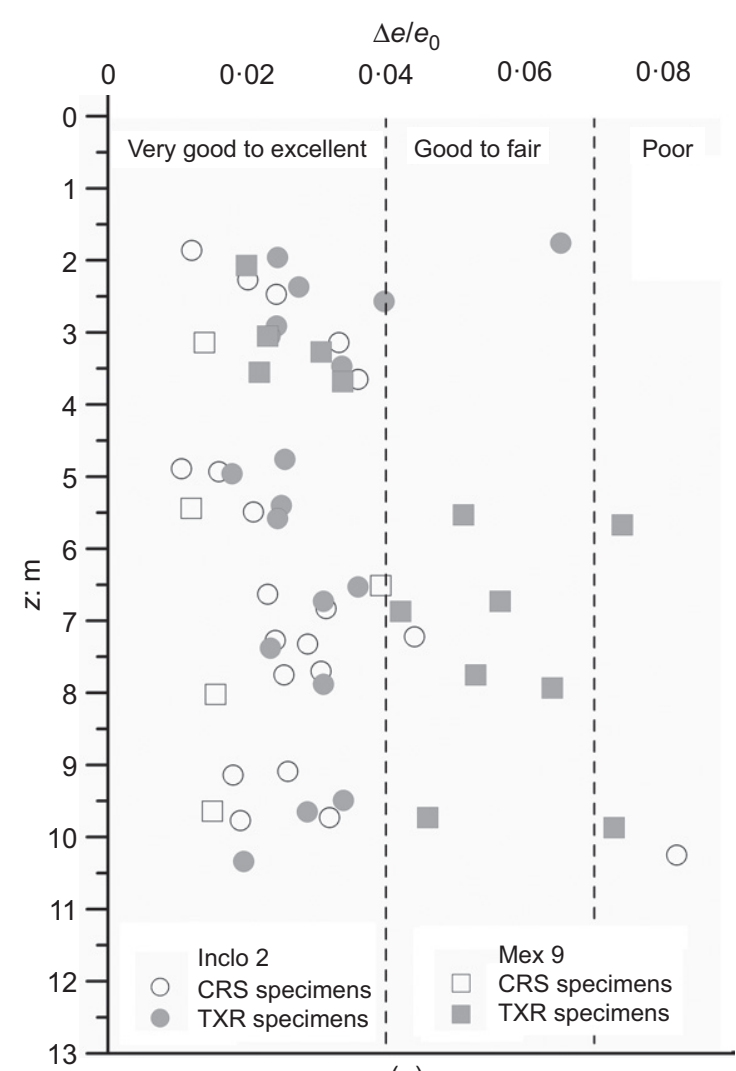

(a)

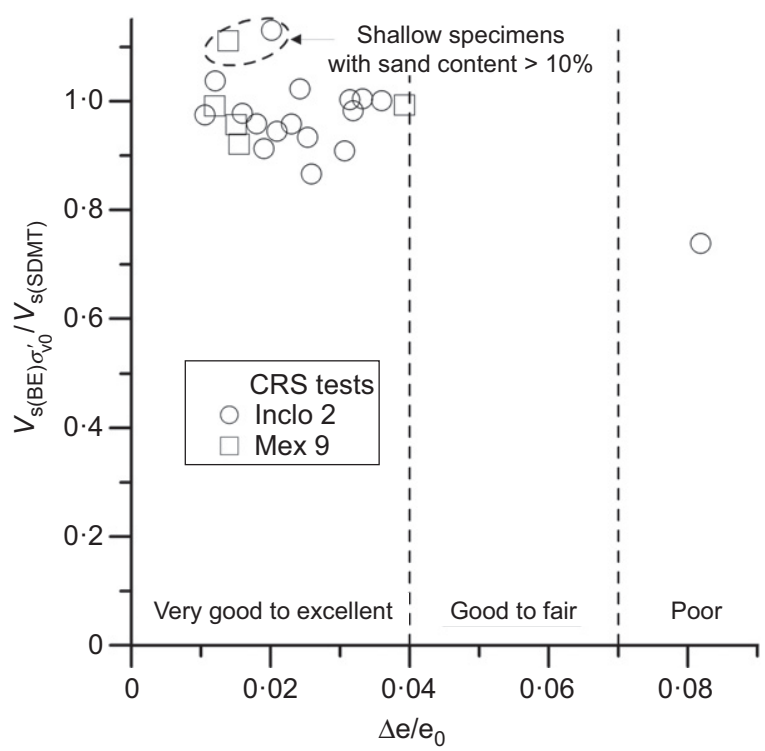

(b)

Fig. 5. Assessment of sample quality for Ballina clay specimens: (a) normalised void ratio; (b) normalised $V_{\text {s }}$ plotted against normalised void ratio

yielding between $3.1 \times 10^{-6}$ and $3.45 \times 10^{-6} \mathrm{~s}^{-1}$. The maximum base excess pore pressure ratio, $u_{\mathrm{b}} / \sigma_{\mathrm{v}}$, ranged typically between 5 and $18 \%$ (in a few cases it reached values of approximately $24 \%$ throughout the test). The initial conditions of the specimens are given in Table 2, which also includes a summary of the CRS test results.

\section{Compressibility curves}

The evolution of the volumetric strain, $\varepsilon_{\mathrm{v}}$, with the vertical effective stress, $\sigma_{\mathrm{v}}^{\prime}$, is shown in Fig. 6 along with the measured excess pore water pressure, $\Delta u_{\mathrm{b}}$. The compressibility curves display a non-linear response in the normally consolidated range $\left(\sigma_{\mathrm{v}}^{\prime}>\sigma_{\text {yield }}^{\prime}\right)$. This behaviour is represented by the $\mathrm{S}$-shape compression curve, which is the consequence of progressive soil destructuration. The largest deformation rate takes place just after passing $\sigma_{\text {yield }}^{\prime}$ and then it reduces with increasing $\sigma_{\mathrm{v}}^{\prime}$. The stress-strain curves for specimens from borehole Mex 9 lie above the curves of those from borehole Inclo 2. This suggests a higher soil stiffness that is consistent with their lower initial void ratio (water content). A small and quasi-linear increase in pore water pressure was registered below $\sigma_{\text {yield. }}^{\prime}$ In the normally consolidated range, a non-linear increase in $\Delta u_{\mathrm{b}}$ was observed. Zero excess pore water pressure was measured for the tests of the shallowest and deepest specimens due to their high sand content. It can be noted that the large compressions registered in the specimens from a depth of $10.35 \mathrm{~m}\left(\sigma_{\mathrm{v}}^{\prime}<100 \mathrm{kPa}\right)$ correspond to the poor quality specimen reported in Fig. 5. The influence of the strain rate on the compressibility of Ballina clay was evaluated in three CRS tests reported in Fig. $6(4.93 \mathrm{~m}$, $6.83 \mathrm{~m}$ and $9.76 \mathrm{~m}$ ) in which a displacement rate five times slower was used (strain rate $\approx 8.33 \times 10^{-7} \mathrm{~s}^{-1}$ ). This produced a reduction in $\sigma_{\text {yield }}^{\prime}$ but no important changes in the compressibility post-yielding. A maximum ratio $u_{\mathrm{b}} / \sigma_{\mathrm{v}}$ about $5 \%$ was registered in these tests.

To compare the compressibility of specimens along the entire profile, the compression curves have been normalised using the void index concept, $I_{\mathrm{v}}=\left(e-e_{100}^{*}\right) / C_{\mathrm{c}}^{*}$, introduced by Burland (1990). The void index requires the determination of two parameters, $e_{100}^{*}$ and $C_{\mathrm{c}}^{*}$, that represent the compressibility of the intrinsic material. Values of $e_{100}^{*}$ and $C_{\mathrm{c}}^{*}$ for the entire profile have been estimated from the void ratio at the LL $\left(e_{\mathrm{L}}\right)$ using Burland's empirical correlations. Fig. 7 shows the normalised compression curves for all the CRS tests, where unloading paths are not given for clarity. Curves for specimens from borehole Inclo 2 are represented by solid lines whereas dashed lines refer to specimens from borehole Mex 9. The intrinsic compression line (ICL) and the sedimentary compression line (SCL), determined by Burland (1990), are included as a point of reference. Results from two additional CRS tests performed on reconstituted clay ( $w=1.3 \times \mathrm{LL}$, without previous soil drying) from $3.0 \mathrm{~m}$ and $7.5 \mathrm{~m}$ depth are included in Fig. 7 to check the location of the ICL. The $I_{\mathrm{v}}-\log \sigma_{\mathrm{v}}^{\prime}$ curves all lie above the ICL, which is indicative of the natural structure of the clay. As the stress level increases beyond $\sigma_{\text {yield }}^{\prime}$, destructuration takes place and the curves tend to converge to the ICL. Two destructuration rates are observed in Fig. 7, depending on the specimen depth. Specimens from borehole Inclo 2 located below $5 \mathrm{~m}$ (black solid lines) shows larger destructuration than shallow specimens (grey solid lines). For stresses higher than $300 \mathrm{kPa}$, all the curves tend toward the ICL showing a gently destructuration rate. The compressibility curve represented by open circles corresponds to a specimen from $4.93 \mathrm{~m}$, which displays large destructuration beyond $\sigma_{\text {yield }}^{\prime}$. This leads to earlier convergence with the curves from shallow specimens, and seems to indicate a change in the level of structure in the clay. The small variations in $w_{\text {nat }}, \rho_{\mathrm{d}}$, EC, clay content, plasticity as well as $\mathrm{Na}^{+}$and $\mathrm{Cl}^{-}$(Fig. 3) observed for the soil below $5 \mathrm{~m}$ seems to confirm this hypothesis.

Figure 8 shows the variation of $\sigma_{\text {yield }}^{\prime}$ with $\sigma_{\mathrm{v} 0}^{\prime}$ for specimens from boreholes Inclo 2 and Mex 9. The strain energy method (Becker et al., 1987) was used to determine $\sigma_{\text {yield }}^{\prime}$, whereas values of $\sigma_{\mathrm{v} 0}^{\prime}$ were estimated from bulk density measurements and ground water level data (Fig. 1(b)). The yielding stresses $\sigma_{\text {yield }}^{\prime}$ are higher than $\sigma_{\mathrm{v} 0}^{\prime}$, which is indicative of an overconsolidated state. It is unlikely that the deposits forming the soil profile at the Ballina site have been subjected to mechanical overconsolidation (unloading) in the past. Therefore, 
Table 2. Results from CRS tests

\begin{tabular}{|c|c|c|c|c|c|c|c|c|c|c|c|c|c|c|c|}
\hline \multirow{2}{*}{$\begin{array}{l}\text { Depth: } \\
\mathrm{m}\end{array}$} & \multirow{2}{*}{$\begin{array}{l}\text { Displ. rate: } \\
\mathrm{mm} / \mathrm{min}\end{array}$} & \multirow[t]{2}{*}{$w_{\text {nat }}: \%$} & \multirow[t]{2}{*}{$e_{0}$} & \multirow{2}{*}{$\begin{array}{l}\sigma_{\mathrm{v} 0}^{\prime}: \\
\mathrm{kPa}\end{array}$} & \multirow{2}{*}{$\begin{array}{l}\sigma_{\text {yield }}^{\prime}: \\
\mathrm{kPa}\end{array}$} & \multirow{2}{*}{$\begin{array}{c}\mathrm{YSR}=\underset{\sigma_{\mathrm{v} 0}^{\prime}}{\sigma_{\mathrm{yield}}^{\prime}} / \\
\end{array}$} & \multirow{2}{*}{$\begin{array}{l}\text { Strain rate at } \\
\text { yielding: } \mathrm{s}^{-1}\end{array}$} & \multirow[t]{2}{*}{$\Delta e / e_{0}$} & \multirow{2}{*}{$\begin{array}{l}V_{\mathrm{s}} \text { at } \sigma_{\mathrm{v} 0}^{\prime}: \\
\mathrm{m} / \mathrm{s}\end{array}$} & \multicolumn{2}{|c|}{$M: \mathrm{kPa}$} & \multicolumn{2}{|c|}{$c_{\mathrm{v}}: \mathrm{m}^{2} /$ year } & \multicolumn{2}{|c|}{$k_{\mathrm{w}}: \mathrm{m} / \mathrm{s}$} \\
\hline & & & & & & & & & & $\begin{array}{c}\text { at } \\
\sigma_{\mathrm{v} 0}^{\prime} \\
\end{array}$ & $\begin{array}{c}\text { at } \\
\sigma_{\text {yield }}^{\prime} \\
\end{array}$ & at $\sigma_{\mathrm{v} 0}^{\prime}$ & $\begin{array}{c}\text { at } \\
\sigma_{\text {yield }}^{\prime} \\
\end{array}$ & at $\sigma_{\mathrm{v} 0}^{\prime}$ & at $\sigma_{\text {yield }}^{\prime}$ \\
\hline \multicolumn{16}{|l|}{ Inclo 2} \\
\hline 0.79 & 0.004 & $30 \cdot 1$ & $1 \cdot 09$ & $8 \cdot 9$ & $36 \cdot 7$ & $4 \cdot 11$ & $2 \cdot 80 \times 10^{-6}$ & 0.053 & $117 \cdot 5$ & 1554 & 2086 & $247 \cdot 1$ & $116 \cdot 7$ & $7 \cdot 41 \times 10^{-8}$ & $1.77 \times 10^{-8}$ \\
\hline 1.86 & & $60 \cdot 80$ & $1 \cdot 64$ & $21 \cdot 0$ & $68 \cdot 55$ & $3 \cdot 26$ & $3.27 \times 10^{-6}$ & 0.012 & $56 \cdot 2$ & 2843 & 733 & $170 \cdot 4$ & - & $1.93 \times 10^{-8}$ & - \\
\hline $2 \cdot 27^{*}$ & & $78 \cdot 3$ & $2 \cdot 03$ & $28 \cdot 0$ & $61 \cdot 1$ & $2 \cdot 18$ & $3.33 \times 10^{-6}$ & 0.020 & $60 \cdot 5$ & 1303 & 938 & $28 \cdot 9$ & $7 \cdot 0$ & $7 \cdot 03 \times 10^{-9}$ & $2.40 \times 10^{-9}$ \\
\hline $2 \cdot 47^{*}$ & & $80 \cdot 21$ & $2 \cdot 14$ & 28.05 & $62 \cdot 1$ & $2 \cdot 22$ & $3 \cdot 27 \times 10^{-6}$ & $0 \cdot 024$ & $59 \cdot 3$ & - & - & - & - & - & - \\
\hline $3 \cdot 14$ & & 88.63 & $2 \cdot 41$ & 28.95 & $51 \cdot 30$ & 1.77 & $3.17 \times 10^{-6}$ & 0.033 & $60 \cdot 3$ & 1140 & 594 & $144 \cdot 7$ & $37 \cdot 6$ & $4.0 \times 10^{-8}$ & $2.0 \times 10^{-8}$ \\
\hline $3 \cdot 65$ & & $88 \cdot 30$ & $2 \cdot 43$ & $31 \cdot 10$ & $57 \cdot 85$ & $1 \cdot 80$ & $3 \cdot 11 \times 10^{-6}$ & 0.036 & $59 \cdot 1$ & 1657 & 719 & 285.9 & $134 \cdot 1$ & $5.47 \times 10^{-8}$ & $5.92 \times 10^{-8}$ \\
\hline $4 \cdot 89$ & & $117 \cdot 4$ & $3 \cdot 10$ & $38 \cdot 10$ & $76 \cdot 03$ & 1.99 & $3 \cdot 20 \times 10^{-6}$ & $0 \cdot 011$ & $60 \cdot 4$ & 2550 & 710 & $24 \cdot 4$ & $2 \cdot 38$ & $3.01 \times 10^{-9}$ & $1.62 \times 10^{-9}$ \\
\hline 4.93 & $0 \cdot 0008$ & $111 \cdot 4$ & 3.03 & 38.0 & $66 \cdot 20$ & 1.75 & $6.71 \times 10^{-7}$ & 0.016 & $60 \cdot 6$ & 1415 & 612 & $23 \cdot 43$ & 24.90 & $5.33 \times 10^{-9}$ & $1.29 \times 10^{-9}$ \\
\hline $5 \cdot 49$ & 0.004 & $107 \cdot 8$ & $2 \cdot 85$ & 40.56 & 71.88 & 1.77 & $3.25 \times 10^{-6}$ & 0.021 & $59 \cdot 5$ & 1655 & 688 & $5 \cdot 26$ & $2 \cdot 33$ & $1.00 \times 10^{-9}$ & $1.07 \times 10^{-9}$ \\
\hline 6.63 & & 118.9 & $3 \cdot 18$ & $46 \cdot 00$ & $76 \cdot 42$ & 1.66 & $3.45 \times 10^{-6}$ & 0.023 & $62 \cdot 3$ & 1477 & 785 & $18 \cdot 7$ & 2.98 & $4.00 \times 10^{-9}$ & $1.20 \times 10^{-9}$ \\
\hline $6 \cdot 83$ & $0 \cdot 0008$ & $121 \cdot 1$ & $3 \cdot 25$ & $46 \cdot 1$ & $71 \cdot 4$ & 1.55 & $6.53 \times 10^{-7}$ & 0.031 & $65 \cdot 2$ & 1332 & 741 & $11 \cdot 8$ & $7 \cdot 30$ & $2 \cdot 80 \times 10^{-9}$ & $2.44 \times 10^{-9}$ \\
\hline $7 \cdot 22$ & 0.004 & $119 \cdot 4$ & $3 \cdot 15$ & 48.64 & $77 \cdot 8$ & 1.60 & $3.12 \times 10^{-6}$ & 0.044 & - & 1334 & 831 & $10 \cdot 3$ & $2 \cdot 23$ & $2.45 \times 10^{-9}$ & $8.52 \times 10^{-10}$ \\
\hline $7 \cdot 27$ & & $126 \cdot 2$ & $3 \cdot 31$ & 48.64 & 78.64 & 1.62 & $3.25 \times 10^{-6}$ & 0.024 & - & 1472 & 715 & $9 \cdot 15$ & $2 \cdot 21$ & $1.97 \times 10^{-9}$ & $9.82 \times 10^{-10}$ \\
\hline $7 \cdot 32$ & & $125 \cdot 2$ & $3 \cdot 27$ & $48 \cdot 75$ & $94 \cdot 1$ & 1.93 & $2.91 \times 10^{-6}$ & 0.029 & - & 2364 & 927 & $5 \cdot 90$ & $1 \cdot 82$ & $7.92 \times 10^{-10}$ & $6.23 \times 10^{-10}$ \\
\hline $7 \cdot 70$ & & $113 \cdot 5$ & $3 \cdot 01$ & $50 \cdot 4$ & $80 \cdot 0$ & 1.59 & $3.4 \times 10^{-6}$ & 0.031 & $61 \cdot 8$ & 1629 & 1081 & 3.87 & $2 \cdot 52$ & $7.52 \times 10^{-10}$ & $7.40 \times 10^{-10}$ \\
\hline $7 \cdot 75$ & & $113 \cdot 5$ & $3 \cdot 00$ & $50 \cdot 45$ & $82 \cdot 0$ & 1.64 & $3.25 \times 10^{-6}$ & 0.025 & $63 \cdot 5$ & 1535 & 787 & $5 \cdot 20$ & 2.67 & $1.05 \times 10^{-9}$ & $1.02 \times 10^{-9}$ \\
\hline $9 \cdot 09$ & & $114 \cdot 6$ & $3 \cdot 06$ & $55 \cdot 77$ & $90 \cdot 10$ & 1.62 & $3.07 \times 10^{-6}$ & $0 \cdot 026$ & $63 \cdot 2$ & 1606 & 771 & 264 & $2 \cdot 95$ & $5 \cdot 22 \times 10^{-8}$ & $1.21 \times 10^{-9}$ \\
\hline $9 \cdot 14$ & & $112 \cdot 4$ & 2.99 & $55 \cdot 87$ & $94 \cdot 38$ & 1.69 & $3.20 \times 10^{-6}$ & $0 \cdot 018$ & $70 \cdot 0$ & 1994 & 1162 & $4 \cdot 11$ & $2 \cdot 76$ & $6.54 \times 10^{-10}$ & $7.52 \times 10^{-10}$ \\
\hline $9 \cdot 73$ & & $106 \cdot 3$ & $2 \cdot 80$ & $57 \cdot 85$ & $104 \cdot 86$ & $1 \cdot 81$ & $3 \cdot 20 \times 10^{-6}$ & 0.032 & $75 \cdot 2$ & 2561 & 972 & 5.95 & 1.83 & $7.40 \times 10^{-10}$ & $6 \cdot 10 \times 10^{-10}$ \\
\hline $9 \cdot 76$ & $0 \cdot 0008$ & $105 \cdot 5$ & $2 \cdot 77$ & $57 \cdot 85$ & $92 \cdot 12$ & 1.59 & $6 \cdot 51 \times 10^{-7}$ & $0 \cdot 019$ & $73 \cdot 0$ & 2350 & 891 & $19 \cdot 36$ & $2 \cdot 7$ & $2.61 \times 10^{-9}$ & $9.63 \times 10^{-10}$ \\
\hline $10 \cdot 25$ & 0.004 & $108 \cdot 0$ & $2 \cdot 83$ & $61 \cdot 15$ & $75 \cdot 37$ & $1 \cdot 33$ & $3 \cdot 25 \times 10^{-6}$ & 0.082 & $66 \cdot 4$ & 859 & 777 & $2 \cdot 54$ & 1.81 & $9 \cdot 38 \times 10^{-10}$ & $7.40 \times 10^{-10}$ \\
\hline $11 \cdot 46$ & & $26 \cdot 2$ & 0.78 & $66 \cdot 1$ & $119 \cdot 75$ & 1.52 & $2.90 \times 10^{-6}$ & 0.032 & $155 \cdot 8$ & 4214 & 6800 & - & - & - & - \\
\hline $12 \cdot 05$ & & $23 \cdot 8$ & $0 \cdot 67$ & $70 \cdot 60$ & $96 \cdot 6$ & $1 \cdot 32$ & $5.62 \times 10^{-7}$ & $0 \cdot 016$ & $179 \cdot 4$ & - & - & - & - & - & - \\
\hline \multicolumn{16}{|l|}{ Mex 9} \\
\hline $1 \cdot 72$ & $0 \cdot 004$ & $33 \cdot 6$ & $0 \cdot 94$ & $21 \cdot 1$ & $53 \cdot 8$ & $2 \cdot 54$ & $2.53 \times 10^{-6}$ & 0.040 & $100 \cdot 1$ & 5520 & 2415 & - & - & - & - \\
\hline $3 \cdot 14$ & & $82 \cdot 6$ & $2 \cdot 16$ & $29 \cdot 0$ & $69 \cdot 0$ & $2 \cdot 37$ & $3.6 \times 10^{-5}$ & $0 \cdot 014$ & $59 \cdot 4$ & - & - & - & - & - & - \\
\hline $5 \cdot 44$ & & 96.8 & $2 \cdot 45$ & $43 \cdot 7$ & $97 \cdot 4$ & $2 \cdot 23$ & $3 \cdot 22 \times 10^{-6}$ & $0 \cdot 012$ & $62 \cdot 0$ & 2570 & 1140 & - & $1 \cdot 65$ & - & $4.57 \times 10^{-10}$ \\
\hline $6 \cdot 51$ & & $99 \cdot 5$ & $2 \cdot 65$ & $47 \cdot 0$ & $78 \cdot 4$ & 1.66 & $3 \cdot 15 \times 10^{-6}$ & 0.039 & $65 \cdot 0$ & 1587 & 870 & $23 \cdot 5$ & $4 \cdot 10$ & $4.70 \times 10^{-9}$ & $1.50 \times 10^{-9}$ \\
\hline $8 \cdot 02$ & & $109 \cdot 5$ & $2 \cdot 89$ & $50 \cdot 0$ & $101 \cdot 7$ & $2 \cdot 03$ & $3 \cdot 21 \times 10^{-6}$ & $0 \cdot 015$ & $63 \cdot 1$ & 2446 & 853 & - & $1 \cdot 24$ & - & $4.60 \times 10^{-10}$ \\
\hline $9 \cdot 64$ & & $88 \cdot 9$ & $2 \cdot 31$ & $58 \cdot 2$ & $108 \cdot 9$ & 1.87 & $3 \cdot 15 \times 10^{-6}$ & $0 \cdot 015$ & $74 \cdot 2$ & 3120 & 1276 & $4 \cdot 75$ & 1.54 & $4.82 \times 10^{-10}$ & $3.82 \times 10^{-10}$ \\
\hline
\end{tabular}

Tests performed using deionised water.

${ }^{*} \mathrm{EC}_{\mathrm{f}}=0 \cdot 45 \mathrm{EC}_{0} ; \mathrm{EC}_{\mathrm{f}}=0 \cdot 60 \mathrm{EC}_{0}$. 

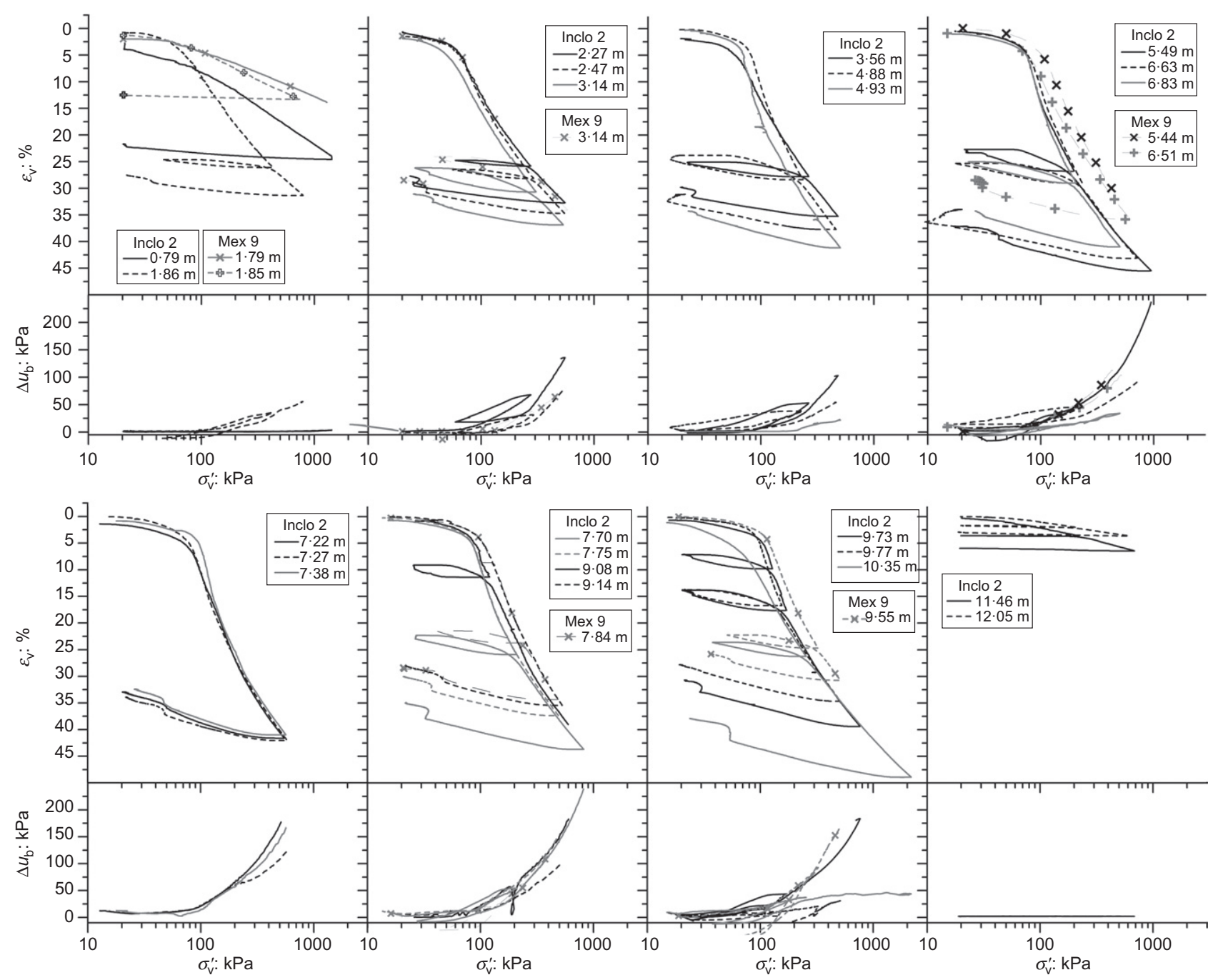

Fig. 6. Compressibility curves from CRS tests

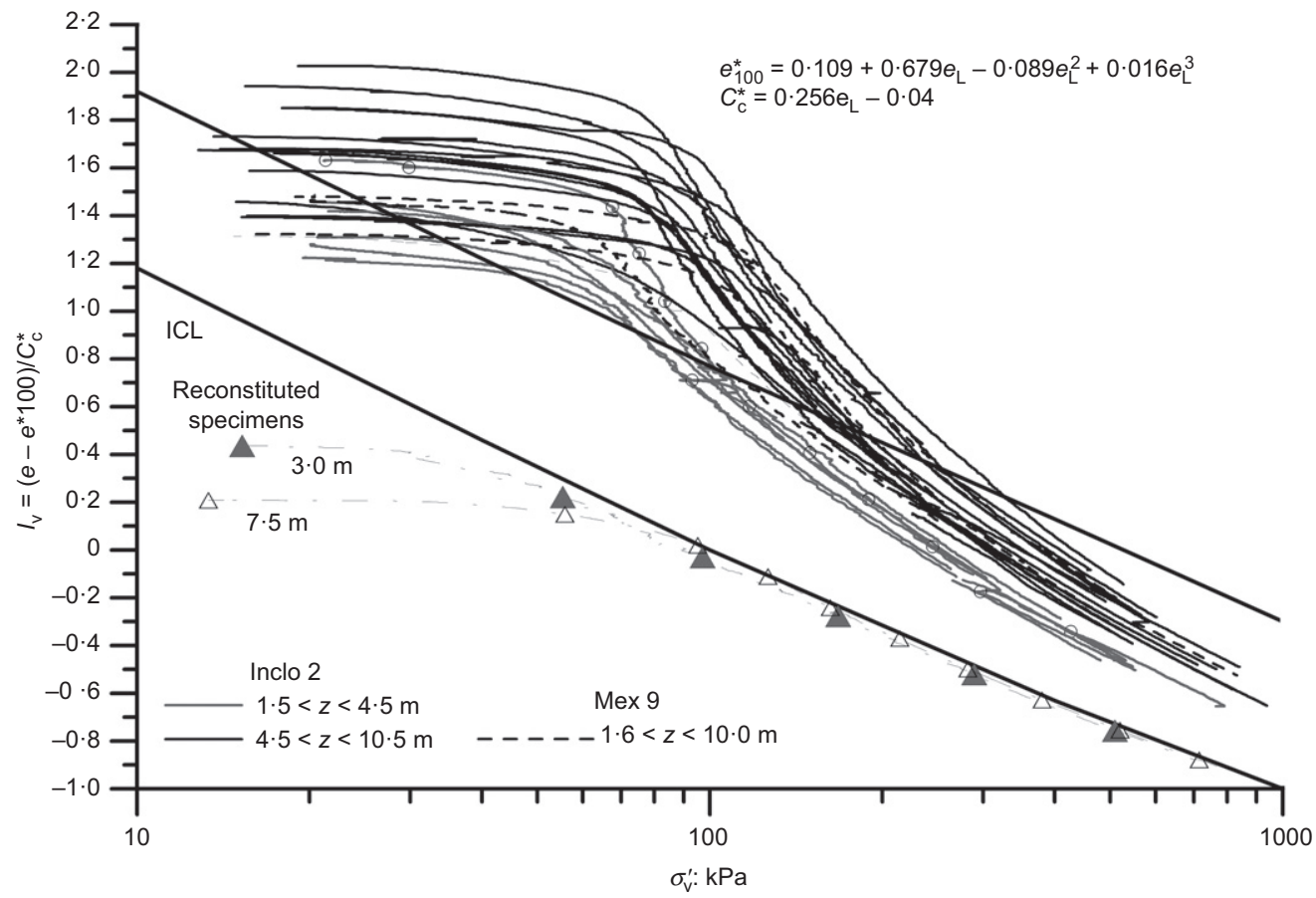

Fig. 7. $I_{v}-\log \sigma_{v}^{\prime}$ plots for CRS tests 


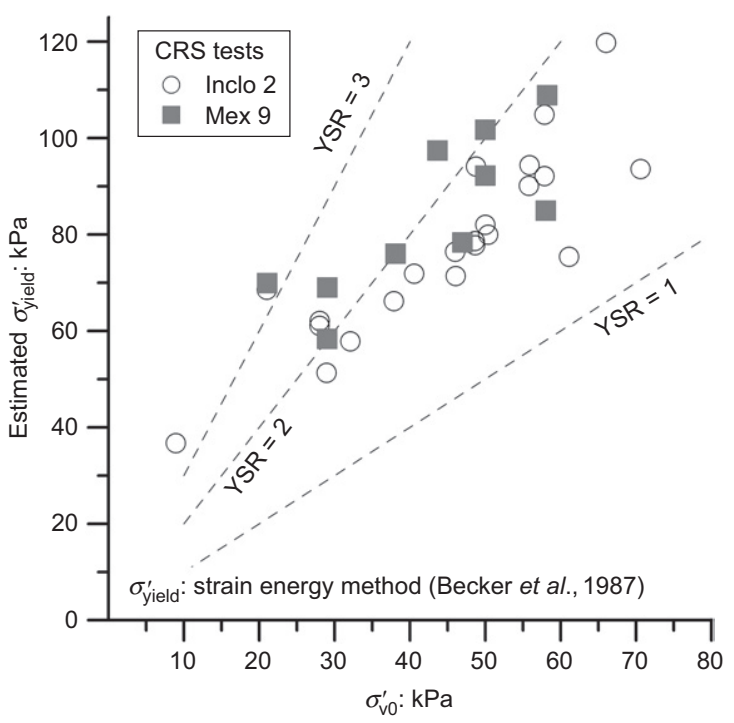

Fig. 8. Variation of yield stress with in situ effective stress the larger values of $\sigma_{\text {yield }}^{\prime}$ are related here to the combined contributions of creep as well as fluctuations in the water level. Larger values of $\sigma_{\text {yield }}^{\prime}$ are observed for specimens from borehole Mex 9. The YSR varies between $1 \cdot 3$ and $3 \cdot 1$, although most of the specimens from borehole Inclo 2 lie between $1 \cdot 3$ and 2 .

Owing to the non-linear response of the compressibility curve, estimating a unique value for the compression index, $C_{\mathrm{c}}$, requires considerable judgement as it may change dramatically with the stress level. Two approaches have been used here to quantify $C_{\mathrm{c}}$ from the CRS results. In the first case, $C_{\mathrm{c}}$ was estimated by deriving the $e-\log \left(\sigma_{\mathrm{v}}^{\prime}\right)$ relationship to obtain a continuous variation of $C_{\mathrm{c}}$ along the loading path $\left(C_{\mathrm{c}}=-\partial e / \partial \log \left(\sigma_{\mathrm{v}}^{\prime}\right)\right)$. In addition, discrete values of $C_{\mathrm{c}}$ were estimated for specific stress levels as $C_{\mathrm{c}}=-\Delta e / \Delta \log \left(\sigma_{\mathrm{v}}^{\prime}\right)$. Results from these two approaches are shown in Fig. 9 as a function of the normalised stress $\sigma_{\mathrm{v}}^{\prime} / \sigma_{\text {yield }}^{\prime}$. Good agreement between both estimation procedures is observed in Fig. 9, in spite of the fact that smaller stress increments could be used to properly capture the strong peak obtained with the continuous approach. The strong influence
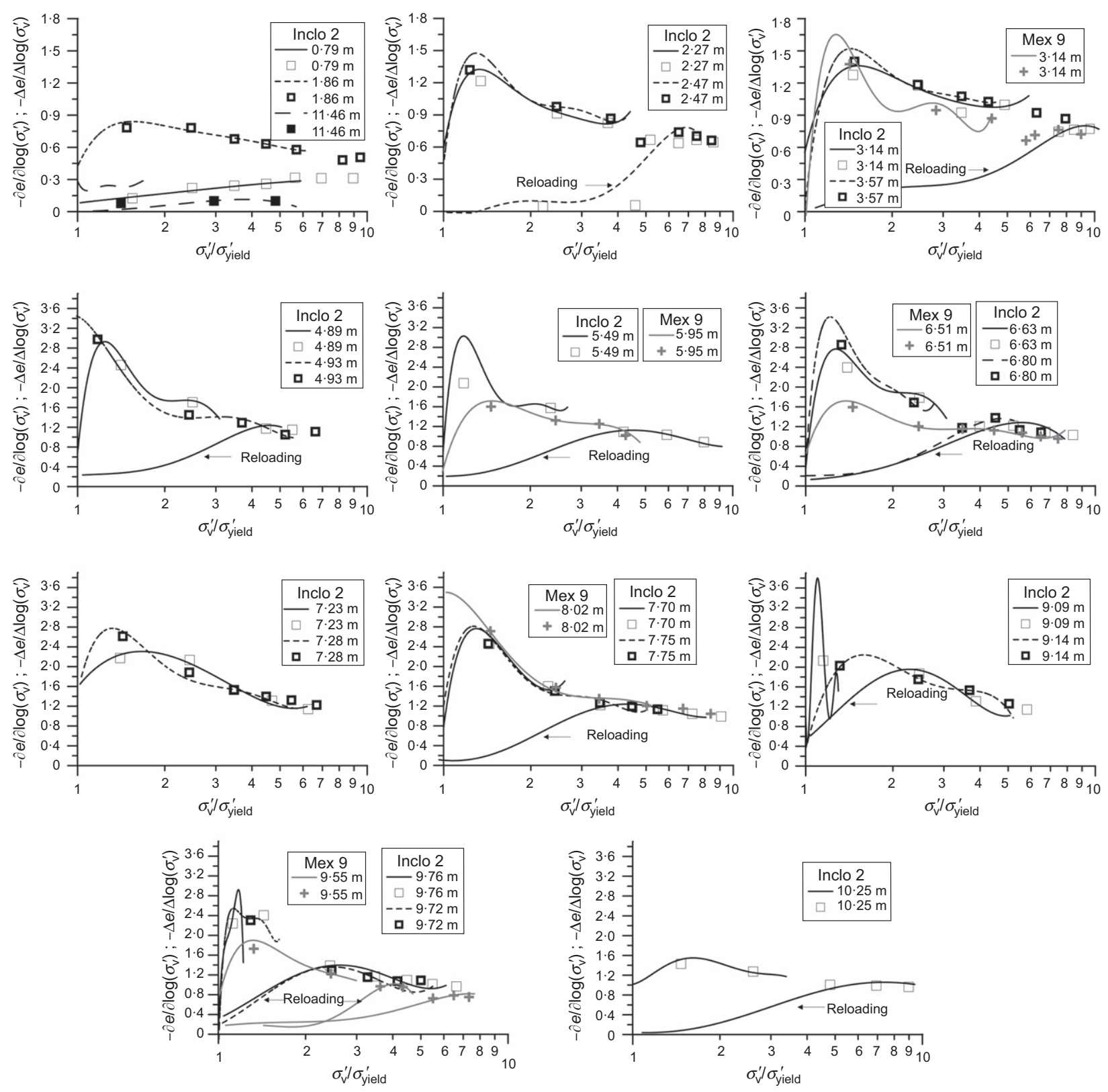

Fig. 9. Variation of $C_{\mathrm{c}}$ with the stress level 
of the stress level on $C_{\mathrm{c}}$ is clear, irrespective of the sample depth. $C_{\mathrm{c}}$ reaches a peak at stresses around $1 \cdot 3-1 \cdot 5$ times $\sigma_{\text {yield }}^{\prime}$ and then decreases progressively with stress. For $\sigma_{\mathrm{v}}^{\prime} / \sigma_{\text {yield }}^{\prime}>5$, values of $C_{\mathrm{c}}$ are similar to those for reconstituted specimens. Values of $C_{\mathrm{c}}$ up to 3.4 have been estimated for specimens between $6 \mathrm{~m}$ and $10 \mathrm{~m}$, which reduces further to $0 \cdot 9-1 \cdot 2$. As recognised previously by various researchers (e.g. Mesri \& Choi, 1985), the strong non-linearity of $C_{\mathrm{c}}$ with the stress level has important practical implications that should be considered in settlement analysis of geotechnical structures.

\section{Consolidation properties}

Figure 10 shows the evolution of the consolidation coefficient, $c_{\mathrm{v}}$, with the vertical effective stress. It has been estimated from the excess pore water pressure registered during CRS tests according to ASTM D4186 (ASTM, 2006). Results of representative specimens from boreholes Inclo 2 and Mex 9 are plotted in Figs 10(a) and 10(b), respectively. Despite some scatter it can be seen that $c_{\mathrm{v}}$ tends to decrease with depth. The $c_{\mathrm{v}}$ reduces as the stress level increases, mainly in the overconsolidated range $\left(\sigma_{\mathrm{v}}^{\prime}<\sigma_{\text {yield }}^{\prime}\right)$ as a consequence of the progressive destructuration. For specimens from Inclo 2 located below $2 \mathrm{~m}$ (Fig. 10(a)), $c_{\mathrm{v}}$ reduces more than one order of magnitude, from around $15 \mathrm{~m}^{2} /$ year to values ranging between 0.3 to $0.85 \mathrm{~m}^{2} /$ year. The minimum variation is observed in the normally consolidated range. A similar response is observed for borehole Mex 9 (Fig. 10(b)), except for the specimen from $3.14 \mathrm{~m}$ where $c_{\mathrm{v}}$ is about twice the value estimated for borehole Inclo 2 .

Results from the CRS tests have been used to estimate the water permeability, $k_{\mathrm{w}}$, of Ballina clay according to ASTM D4186 (ASTM, 2006). Fig. 11 shows the relationship between the void ratio, $e$, and water permeability, $k_{\mathrm{w}}$. Data presented in this figure correspond to loading paths only. The permeability $k_{\mathrm{w}}$ reduces with reducing void ratio and shows a quasi-linear variation in a semi-log plot. For specimens from borehole Inclo $2, k_{\mathrm{w}}$ ranges between $10^{-8}$ and $10^{-11} \mathrm{~m} / \mathrm{s}$ (Fig. 11(a)). Clear differences are observed between specimens below and above $5 \mathrm{~m}$ depth, which confirms a change in soil structure at this level. Deeper specimens, enclosed by dotted lines, have a permeability change index, $C_{\mathrm{k}}=\Delta e / \Delta \log \left(k_{\mathrm{w}}\right)$, of $1 \cdot 125$ $\left(0 \cdot 8<C_{\mathrm{k}}<1 \cdot 2\right)$. For shallow specimens, $C_{\mathrm{k}}$ varies in the range $0 \cdot 2-0 \cdot 5$. Fig. 11(b) compares the variation of $k_{\mathrm{w}}$ with $e$ for specimens with similar depths from boreholes Inclo 2 and Mex 9. For the same void ratio, larger values of $k_{\mathrm{w}}$ are observed for specimens from borehole Mex 9.

\section{Creep behaviour}

Incremental loading (IL) tests were performed to study the secondary compression behaviour of Ballina clay. Creep tests were performed in oedometer cells which are similar to those used in the CRS tests. Long-term loading steps (5 days) were applied during the IL tests until a maximum vertical effective stress of around $215 \mathrm{kPa}$ was reached. This corresponds to stresses between 3.5 and $16 \cdot 5$ times $\sigma_{\mathrm{v} 0}^{\prime}$ (a maximum stress of $448 \mathrm{kPa}$ was applied to the shallowest specimen). Specimens were compressed in steps by doubling the previous load increment according to ASTM D2435 (ASTM, 2011). A small back-water pressure of $4 \mathrm{kPa}$ was maintained through the top and bottom drainage lines to minimise changes in pore fluid salinity due to evaporation during the tests. Table 3 summarises the initial conditions of the specimens tested. Analysis of the displacement plotted against log $(t)$ plots showed that primary consolidation was predominant only for stresses above $\sigma_{\text {yield }}^{\prime}$, whereas secondary compression was observed for all loading increments.

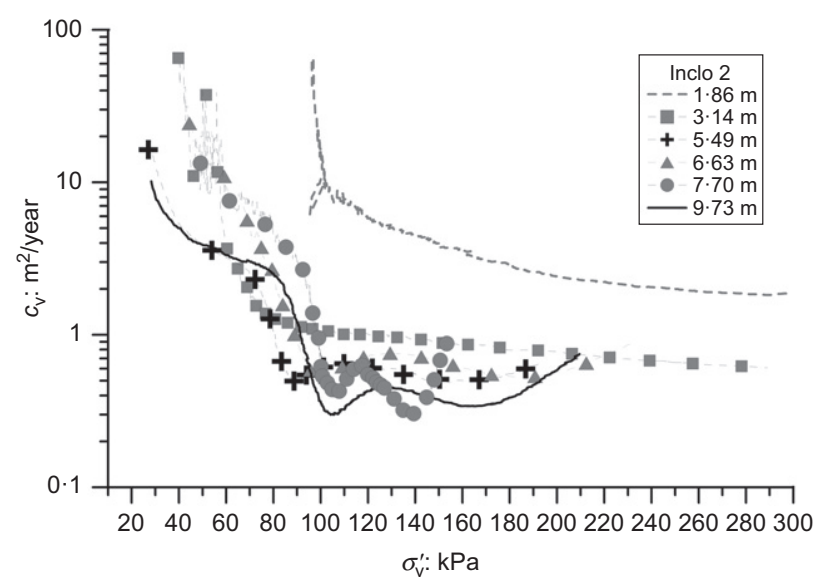

(a)

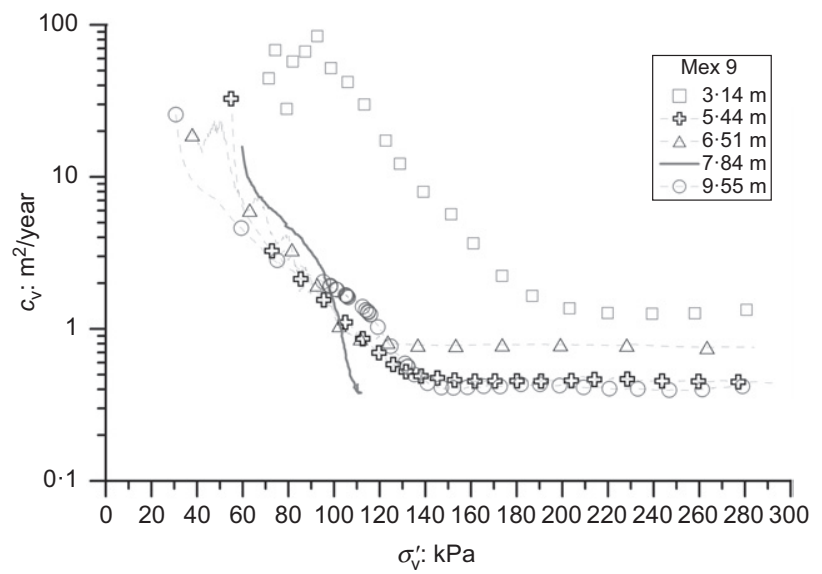

(b)

Fig. 10. Variation of $c_{\mathrm{v}}$ during CRS loading: (a) specimens from borehole Inclo 2; (b) specimens from borehole Mex 9

Figure 12 shows the compressibility curves, $e-\log \left(\sigma_{\mathrm{v}}^{\prime}\right)$, for seven specimens from borehole Inclo 2, that were used to estimate the coefficient of secondary compression, $C_{\alpha}=\Delta e / \Delta \log (t)$, and the compression index $C_{\mathrm{c}}=\Delta e / \Delta \log$ $\left(\sigma_{\mathrm{v}}^{\prime}\right)$. Values of $C_{\alpha}$ lower than $0 \cdot 2$ have been estimated for stresses below yielding. This quantity increases up to $0 \cdot 4-0 \cdot 8$ for stresses around $\sigma_{\text {yield }}^{\prime}$. After yielding, $C_{\alpha}$ ranges between $0 \cdot 25$ and $0 \cdot 40$. Fig. 12 also shows that, except for stresses closer to yielding, the values of $C_{\alpha} / C_{\mathrm{c}}$ vary in a narrow band between 0.025 and $0 \cdot 05$. This response is in agreement with the variation of $C_{\alpha} / C_{\mathrm{c}}$ found by Mesri \& Godlewski (1977) for several clays. The main results are included in Table 3.

\section{Variation of $\sigma_{\text {yield, }}^{\prime} Y S R, \mathrm{~V}_{s}, \mathrm{M}, \mathrm{c}_{v}$ and $\mathrm{k}_{w}$ with depth}

Figure 13 shows the variation with depth of the mechanical parameters obtained from CRS tests for boreholes Inclo 2 and Mex 9. The variation of $\sigma_{\text {yield }}^{\prime}$ with depth is shown in Fig. 13(a). The yield stress is higher than $\sigma_{\mathrm{v} 0}^{\prime}$, although a parallel variation with depth is observed below $3 \mathrm{~m}$. This suggests minor variations in the degree of soil structure as observed in Fig. 13(b). The yield stress ratio reduces from around 3 (at shallow depths) towards a quasi-constant value of around 1.5-1.6 for borehole Inclo 2. Larger values are observed for borehole Mex 9, which is consistent with the differences in the water content (void ratio) reported in Fig. 3. It is important to note that the values of $\sigma_{\text {yield }}^{\prime}$ reported in Fig. 13(a) have not been corrected for strain rate effects. To include the influence of the strain rate on $\sigma_{\text {yield }}^{\prime}$, a number of approaches may be used (e.g. Mesri \& Feng, 1992; Watabe et al., 2012). According to Watabe et al. (2012), a correction 


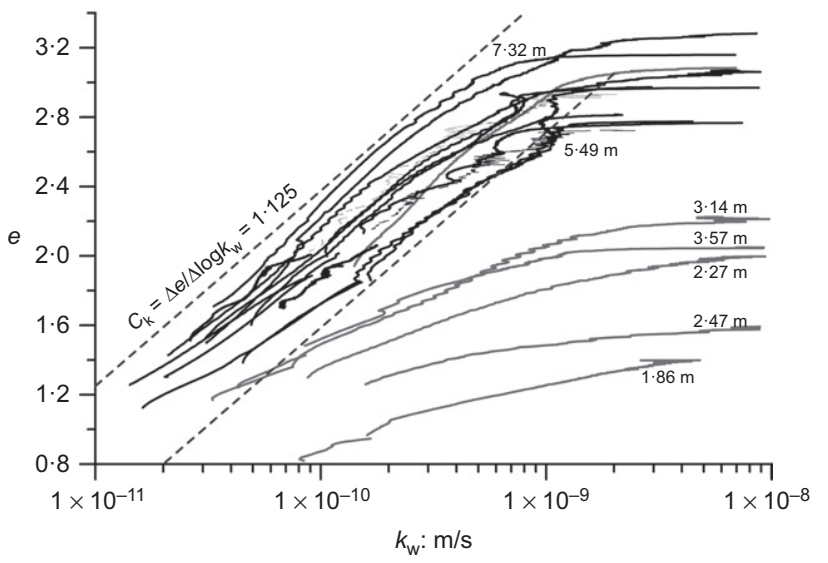

(a)

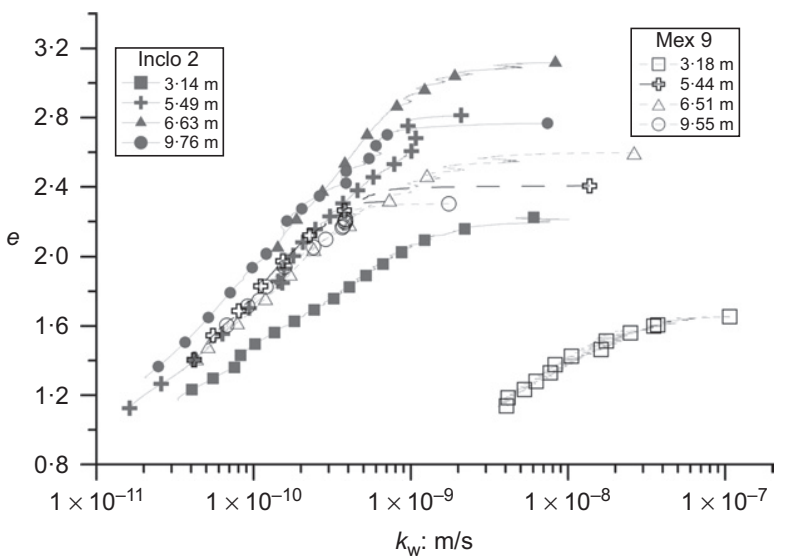

(b)

Fig. 11. Variation of $k_{\mathrm{w}}$ during CRS loading: (a) specimens from borehole Inclo 2; (b) comparison between borehole Inclo 2 and borehole Mex 9

factor of around $0 \cdot 84$ should be applied to the values of $\sigma_{\text {yield }}^{\prime}$ in Fig. 13(a).

The profile of $V_{\mathrm{s}}$ determined at $\sigma_{\mathrm{v} 0}^{\prime}$ during CRS tests using bender element transducers is shown in Fig. 13(c). This figure also includes results from two SDMT tests (SDMT-1 and SDMT-34) performed at locations indicated in Fig. 1(b) for the purpose of comparison. A good match is observed between the laboratory and in situ data along the soil profile, which confirms the good quality of the specimens tested in this investigation. The shear wave velocity appears to vary linearly with depth between $3 \mathrm{~m}(\approx 60.3 \mathrm{~m} / \mathrm{s})$ and $10.5 \mathrm{~m}$ $(\approx 73 \mathrm{~m} / \mathrm{s})$. The laboratory data also capture the increase in $V_{\mathrm{s}}$ detected in SDMT-1 at depths below $11 \mathrm{~m}$, where a sand layer appears. Fig. 13(d) shows the variation of $M$ with depth estimated from CRS tests at both $\sigma_{\mathrm{v} 0}^{\prime}$ and $\sigma_{\text {yield. Some }}^{\prime}$ dispersion is observed for values of $M$ estimated at $\sigma_{\mathrm{v} 0}^{\prime}$. $M$ varies between 1150 and $3200 \mathrm{kPa}$ over depths of $2 \mathrm{~m}$ to $10.5 \mathrm{~m}$, with the sandy layers showing values of $M$ ranging

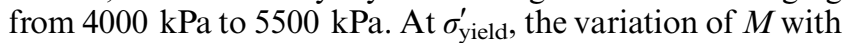
depth is more uniform and lies between 600 and $1300 \mathrm{kPa}$.

Estimates of $c_{\mathrm{v}}$ at $\sigma_{\mathrm{v} 0}^{\prime}$ and $\sigma_{\text {yield }}^{\prime}$ are presented in Fig. 13(e), where it is shown that $c_{\mathrm{v}}$ decreases with depth. More scatter is observed for values of $c_{\mathrm{v}}$ at $\sigma_{\mathrm{v} 0}^{\prime}$, especially for the shallow specimens. For $z<4 \mathrm{~m}, c_{\mathrm{v}}$ ranges from $8 \mathrm{~m}^{2} /$ year to values larger than $100 \mathrm{~m}^{2} /$ year. This range reduces to $5-25 \mathrm{~m}^{2} /$ year $\left(c_{\mathrm{v} \text {-average }} \approx 7 \mathrm{~m}^{2} /\right.$ year $)$ in specimens below $4 \mathrm{~m}$. The average $c_{\mathrm{v}}$ reduces to $3 \mathrm{~m}^{2} /$ year at $\sigma_{\text {yield }}^{\prime}$. Values of $c_{\mathrm{v}}$ estimated from creep tests (filled crosses) show a similar trend and define a lower boundary between $0.5 \mathrm{~m}^{2} /$ year and $7 \mathrm{~m}^{2} /$ year (a larger value is observed in sandy specimens). As observed in Fig. 13(f), $k_{\mathrm{w}}$ varies according to the response of $c_{\mathrm{v}}$
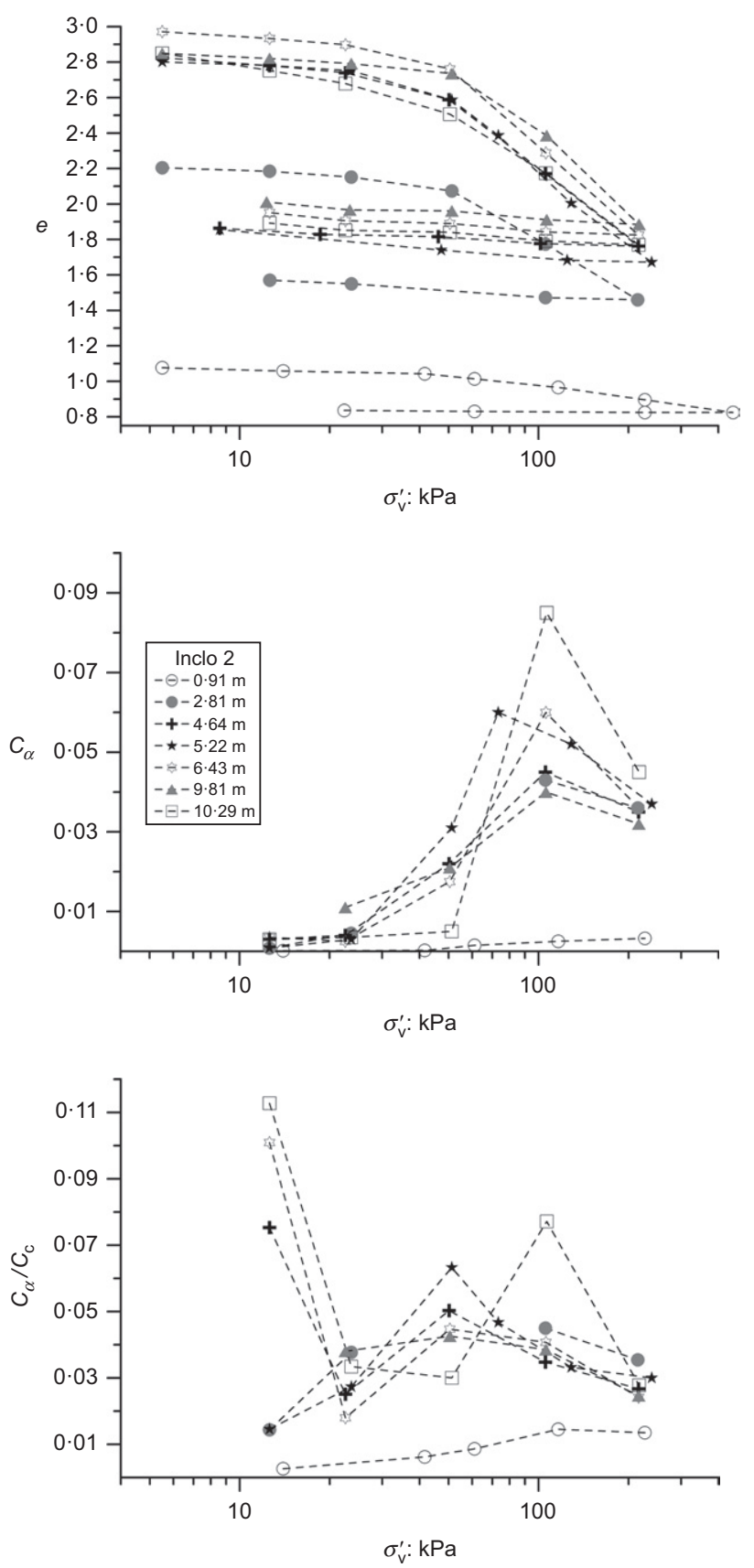

Fig. 12. Results from IL (creep) tests on specimens from borehole Inclo 2

Table 3. Results from IL-creep tests

\begin{tabular}{|c|c|c|c|c|c|}
\hline Depth: $m$ & $w_{\text {nat }}: \%$ & $e_{0}$ & $C_{\mathrm{s}}$ & $\begin{array}{l}c_{\mathrm{v}} \text { at } \sigma_{\mathrm{v} 0}^{\prime}: \\
\mathrm{m}^{2} / \text { year }\end{array}$ & $\begin{array}{c}k_{\mathrm{w}} \text { at } \sigma_{\mathrm{v} 0}^{\prime}: \\
\mathrm{m} / \mathrm{s}\end{array}$ \\
\hline \multicolumn{6}{|l|}{ Inclo 2} \\
\hline 0.91 & $30 \cdot 81$ & 1.08 & $0 \cdot 009$ & 157 & $1.50 \times 10^{-9}$ \\
\hline $2 \cdot 8$ & & $2 \cdot 2$ & $0 \cdot 0$ & 4 & $6.75 \times 10^{-10}$ \\
\hline $4 \cdot 64$ & $107 \cdot 14$ & $2 \cdot 82$ & 0.072 & 2 . & $4.46 \times 10^{-10}$ \\
\hline $5 \cdot 22$ & 105. & $2 \cdot 80$ & $0 \cdot 132$ & 4. & $9 \cdot 20 \times 10^{-10}$ \\
\hline $6 \cdot 43$ & $110 \cdot 45$ & 2.97 & $0 \cdot 100$ & $2 \cdot 02$ & $5.44 \times 10^{-10}$ \\
\hline $9 \cdot 81$ & 10 & $2 \cdot 8$ & 0.097 & 4. & $5.93 \times 10^{-10}$ \\
\hline $10 \cdot 29$ & $107 \cdot 5$ & $2 \cdot 85$ & 0.097 & $0 \cdot 48$ & $2.37 \times 10^{-10}$ \\
\hline
\end{tabular}

described above. For the CRS tests, the estimated $k_{\mathrm{w}}$ ranges between $8 \times 10^{-9}$ and $2 \times 10^{-8} \mathrm{~m} / \mathrm{s}(z<4 \mathrm{~m})$. It reduces with depth from $4 \times 10^{-9}$ to around $3 \times 10^{-10} \mathrm{~m} / \mathrm{s}$. The water 
Table 4. Summary of triaxial tests

\begin{tabular}{|c|c|c|c|c|c|c|c|c|c|c|c|c|}
\hline Depth: m & Test type & $w_{\text {nat }}: \%$ & $e_{0}$ & $\sigma_{\mathrm{v}-\text { cons }}^{\prime}: \mathrm{kPa}$ & $\varepsilon_{\mathrm{vol}-\mathrm{cons}}: \%$ & $\Delta e / e_{0}$ & $q_{\text {peak }}: \mathrm{kPa}$ & $\varepsilon_{\text {a-peak }}: \%$ & $q / p^{\prime}$ at peak & $s_{\mathrm{u}}: \mathrm{kPa}$ & $\begin{aligned} I_{\mathrm{B}}= & {\left[\left(q_{\text {peak }}-q_{\text {post-rupture }}\right) / q_{\text {peak }}\right] } \\
& \times 100: \%\end{aligned}$ & $I_{\mathrm{r}}=G_{\mathrm{u} 50} / s_{\mathrm{u}}$ \\
\hline \multicolumn{13}{|l|}{ Inclo 2} \\
\hline $1 \cdot 76$ & $\operatorname{TC}\left(K_{0}\right)$ & $57 \cdot 32$ & $1 \cdot 54$ & $20 \cdot 2$ & $3 \cdot 96$ & $0 \cdot 065$ & $18 \cdot 7$ & $7 \cdot 13$ & $1 \cdot 25$ & $9 \cdot 4$ & $21 \cdot 4$ & 23 \\
\hline $1 \cdot 96$ & & $65 \cdot 14$ & $1 \cdot 75$ & $21 \cdot 6$ & $1 \cdot 55$ & 0.024 & $24 \cdot 6$ & $2 \cdot 95$ & $1 \cdot 37$ & $12 \cdot 3$ & $52 \cdot 3$ & 23 \\
\hline $2 \cdot 37^{\epsilon}$ & & 78.09 & $2 \cdot 11$ & $28 \cdot 3$ & 1.86 & 0.027 & $34 \cdot 5$ & $1 \cdot 41$ & 1.59 & $17 \cdot 2$ & $37 \cdot 8$ & 73 \\
\hline $2 \cdot 57^{\epsilon}$ & & $86 \cdot 31$ & $2 \cdot 30$ & $28 \cdot 2$ & $2 \cdot 77$ & $0 \cdot 040$ & $26 \cdot 6$ & $1 \cdot 88$ & $1 \cdot 30$ & $13 \cdot 3$ & $47 \cdot 2$ & 87 \\
\hline $2 \cdot 91$ & & $88 \cdot 11$ & $2 \cdot 40$ & $28 \cdot 3$ & 1.71 & 0.024 & $27 \cdot 3$ & $1 \cdot 43$ & $1 \cdot 19$ & $13 \cdot 7$ & $51 \cdot 0$ & 87 \\
\hline $3 \cdot 05$ & & $83 \cdot 25$ & $2 \cdot 27$ & $27 \cdot 0$ & $1 \cdot 62$ & 0.023 & $29 \cdot 6$ & $1 \cdot 50$ & $1 \cdot 49$ & $14 \cdot 8$ & $32 \cdot 9$ & 86 \\
\hline $3 \cdot 47$ & $\mathrm{TC}\left(\Delta \varepsilon_{\mathrm{r}}=0\right)$ & $95 \cdot 03$ & $2 \cdot 64$ & $31 \cdot 7$ & $2 \cdot 44$ & 0.034 & $23 \cdot 4$ & 1.03 & $1 \cdot 40$ & $11 \cdot 7$ & $53 \cdot 2$ & 102 \\
\hline $4 \cdot 76$ & $\mathrm{TC}\left(K_{0}\right)$ & $98 \cdot 32$ & $2 \cdot 65$ & 37.9 & $1 \cdot 85$ & $0 \cdot 025$ & $35 \cdot 4$ & $1 \cdot 36$ & $1 \cdot 29$ & $17 \cdot 7$ & $51 \cdot 9$ & 82 \\
\hline 4.96 & $\mathrm{TC}\left(\Delta \varepsilon_{\mathrm{r}}=0\right)$ & $107 \cdot 69$ & $3 \cdot 00$ & $37 \cdot 4$ & $1 \cdot 34$ & 0.018 & $43 \cdot 6$ & $1 \cdot 52$ & 1.75 & $21 \cdot 8$ & $54 \cdot 6$ & 68 \\
\hline $5 \cdot 40$ & $\operatorname{TC}\left(K_{0}\right)$ & $103 \cdot 20$ & $2 \cdot 76$ & $41 \cdot 0$ & $1 \cdot 83$ & 0.025 & $37 \cdot 5$ & $0 \cdot 93$ & $1 \cdot 66$ & $18 \cdot 8$ & $47 \cdot 3$ & 113 \\
\hline $5 \cdot 58$ & & $103 \cdot 75$ & $2 \cdot 74$ & $39 \cdot 2$ & 1.79 & $0 \cdot 024$ & $41 \cdot 8$ & $1 \cdot 20$ & $1 \cdot 83$ & $20 \cdot 9$ & $51 \cdot 6$ & 86 \\
\hline $6 \cdot 53$ & & $113 \cdot 36$ & $3 \cdot 08$ & $44 \cdot 1$ & $2 \cdot 72$ & 0.036 & $45 \cdot 6$ & $0 \cdot 84$ & $2 \cdot 06$ & $22 \cdot 8$ & $56 \cdot 5$ & 93 \\
\hline $6 \cdot 73$ & $\mathrm{TC}\left(\Delta \varepsilon_{\mathrm{r}}=0\right)$ & $113 \cdot 21$ & $3 \cdot 08$ & $46 \cdot 0$ & $2 \cdot 34$ & 0.031 & $39 \cdot 5$ & $1 \cdot 39$ & $1 \cdot 23$ & $19 \cdot 7$ & $43 \cdot 1$ & 70 \\
\hline $7 \cdot 38^{\epsilon}$ & $\mathrm{TC}\left(K_{0}\right)$ & $117 \cdot 33$ & $3 \cdot 13$ & 47.9 & 1.77 & 0.023 & $48 \cdot 1$ & $1 \cdot 20$ & $1 \cdot 89$ & $24 \cdot 0$ & $49 \cdot 8$ & 73 \\
\hline $7 \cdot 88$ & $\mathrm{TC}\left(\Delta \varepsilon_{\mathrm{r}}=0\right)$ & $119 \cdot 37$ & $3 \cdot 18$ & $49 \cdot 0$ & $2 \cdot 36$ & 0.031 & $44 \cdot 9$ & $0 \cdot 23$ & 1.98 & $22 \cdot 4$ & $48 \cdot 0$ & 126 \\
\hline $9 \cdot 49$ & $\operatorname{TC}\left(K_{0}\right)$ & $101 \cdot 73$ & $2 \cdot 68$ & $56 \cdot 8$ & $2 \cdot 47$ & 0.034 & $42 \cdot 6$ & $0 \cdot 60$ & $1 \cdot 30$ & $21 \cdot 3$ & $56 \cdot 2$ & 135 \\
\hline $9 \cdot 65$ & & $103 \cdot 04$ & $2 \cdot 74$ & $56 \cdot 2$ & $2 \cdot 10$ & 0.029 & $49 \cdot 3$ & $0 \cdot 90$ & $1 \cdot 40$ & $24 \cdot 7$ & $46 \cdot 0$ & 92 \\
\hline $10 \cdot 34$ & & $97 \cdot 75$ & $2 \cdot 63$ & $35 \cdot 0$ & 1.42 & 0.020 & $37 \cdot 5$ & $0 \cdot 64$ & $1 \cdot 50$ & $18 \cdot 7$ & $44 \cdot 3$ & 128 \\
\hline \multicolumn{13}{|l|}{ Mex 9} \\
\hline $2 \cdot 07$ & $\mathrm{TC}\left(K_{0}\right)$ & $40 \cdot 88$ & $1 \cdot 12$ & $20 \cdot 8$ & $1 \cdot 05$ & 0.012 & $20 \cdot 98$ & $2 \cdot 63$ & $1 \cdot 41$ & $10 \cdot 5$ & $43 \cdot 8$ & 86 \\
\hline $3 \cdot 05$ & & $81 \cdot 60$ & $2 \cdot 18$ & $26 \cdot 5$ & 1.58 & 0.023 & $32 \cdot 36$ & $1 \cdot 30$ & 1.67 & $16 \cdot 2$ & $52 \cdot 7$ & 96 \\
\hline $3 \cdot 55$ & $\operatorname{TE}\left(K_{0}\right)$ & $88 \cdot 35$ & $2 \cdot 37$ & $26 \cdot 7$ & 1.53 & 0.022 & $-21 \cdot 21$ & $2 \cdot 08$ & $-1 \cdot 18$ & $10 \cdot 6$ & - & - \\
\hline $5 \cdot 53$ & & $89 \cdot 20$ & $2 \cdot 41$ & $4 \cdot 0$ & $3 \cdot 62$ & $0 \cdot 051$ & $-26 \cdot 24$ & $3 \cdot 12$ & $-1 \cdot 28$ & $13 \cdot 1$ & - & - \\
\hline $5 \cdot 67$ & $\operatorname{TC}\left(K_{0}\right)$ & $97 \cdot 75$ & $2 \cdot 63$ & $39 \cdot 3$ & $5 \cdot 36$ & $0 \cdot 074$ & $40 \cdot 48$ & 1.07 & $1 \cdot 64$ & $20 \cdot 2$ & $56 \cdot 9$ & 111 \\
\hline 6.73 & $\operatorname{TE}\left(K_{0}\right)$ & $107 \cdot 90$ & $2 \cdot 88$ & $44 \cdot 3$ & $4 \cdot 19$ & 0.056 & $-27 \cdot 55$ & $3 \cdot 41$ & $-1 \cdot 00$ & $13 \cdot 8$ & - & - \\
\hline 6.87 & $\operatorname{TC}\left(K_{0}\right)$ & $102 \cdot 15$ & 2.68 & $45 \cdot 5$ & 3.07 & $0 \cdot 042$ & $41 \cdot 53$ & $1 \cdot 18$ & 1.69 & $20 \cdot 8$ & $50 \cdot 7$ & 98 \\
\hline $7 \cdot 75$ & & $108 \cdot 70$ & $2 \cdot 95$ & $47 \cdot 8$ & $3 \cdot 24$ & 0.052 & $35 \cdot 35$ & $0 \cdot 76$ & $1 \cdot 26$ & $17 \cdot 7$ & $43 \cdot 4$ & 133 \\
\hline $7 \cdot 93$ & $\operatorname{TE}\left(K_{0}\right)$ & $109 \cdot 55$ & $2 \cdot 91$ & $49 \cdot 6$ & $4 \cdot 76$ & $0 \cdot 063$ & $-34 \cdot 0$ & 3.62 & $-1 \cdot 26$ & $17 \cdot 0$ & - & - \\
\hline $9 \cdot 73$ & $\operatorname{TC}\left(K_{0}\right)$ & $90 \cdot 21$ & $2 \cdot 37$ & $56 \cdot 2$ & 3.95 & $0 \cdot 046$ & $52 \cdot 64$ & $0 \cdot 70$ & 1.68 & $26 \cdot 3$ & $42 \cdot 9$ & 155 \\
\hline $9 \cdot 87$ & $\operatorname{TE}\left(K_{0}\right)$ & $116 \cdot 0$ & 3.07 & $56 \cdot 2$ & $5 \cdot 50$ & 0.073 & $-35 \cdot 0$ & $3 \cdot 62$ & $-1 \cdot 04$ & $17 \cdot 5$ & - & - \\
\hline
\end{tabular}

Tests performed using deionised water. Maximum reduction in EC around 12\%. 


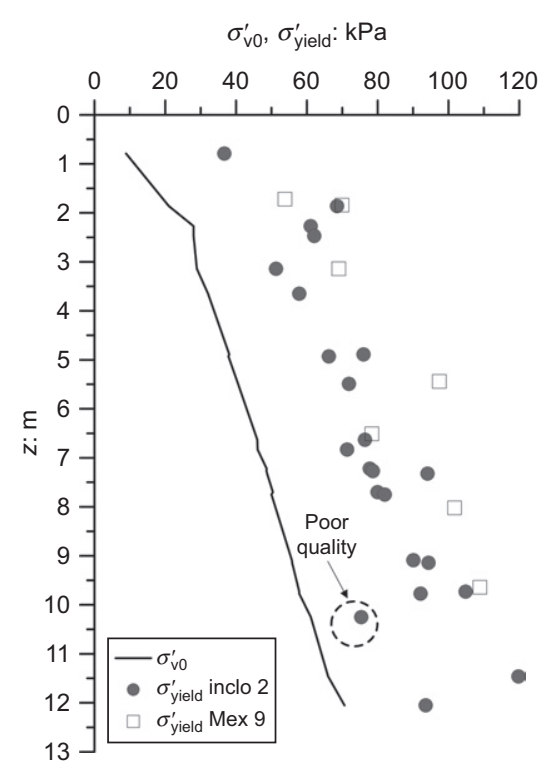

(a)

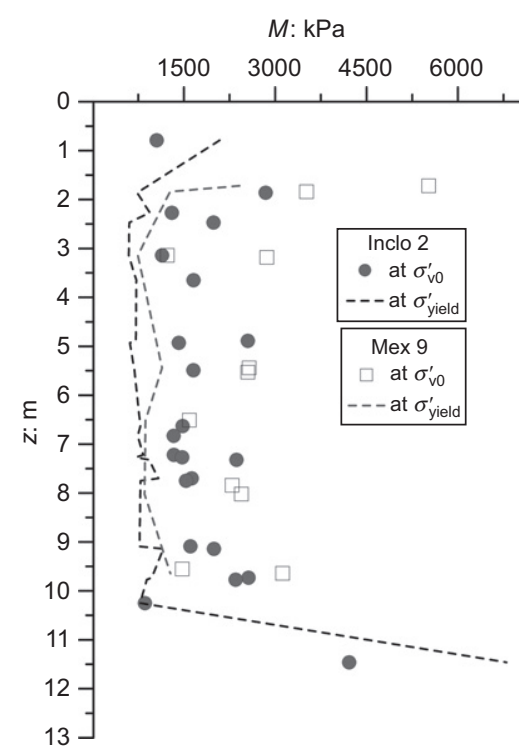

(d)

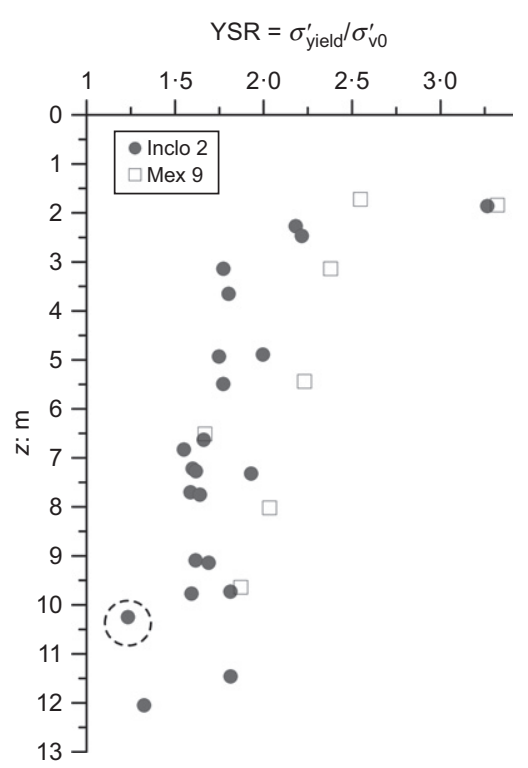

(b)

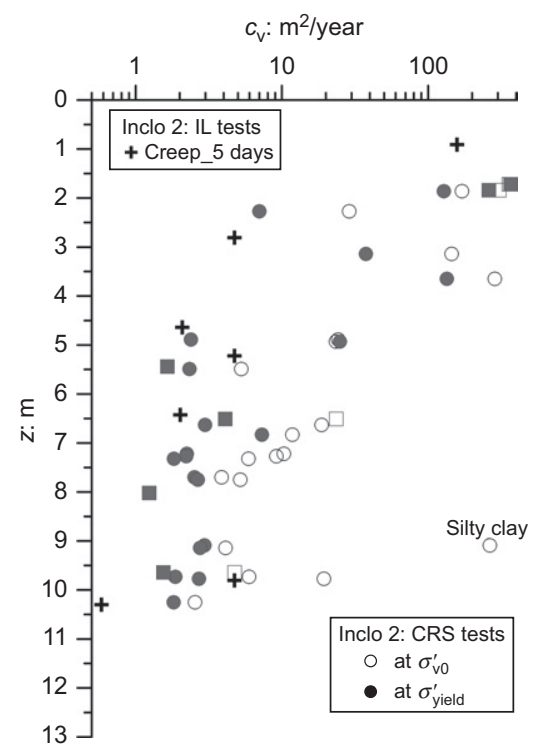

(e)

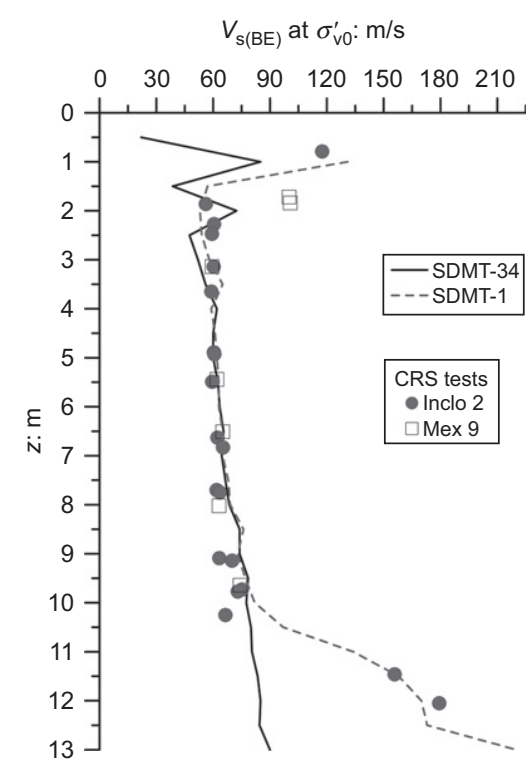

(c)

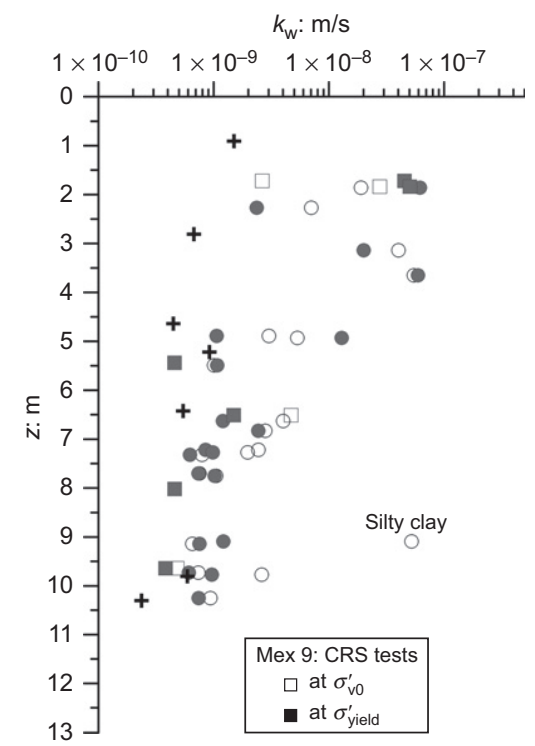

(f)

Fig. 13. Geotechnical profiles for boreholes Inclo 2 and Mex 9: (a) in situ and yield stresses, (b) yield stress ratio, (c) shear wave velocity at in situ stress, (d) constrained modulus, (e) coefficient of consolidation, (f) permeability

permeability decreases by a factor of 3 between $\sigma_{\mathrm{v} 0}^{\prime}$ and $\sigma_{\text {yield }}^{\prime}$, whereas the $k_{\mathrm{w}}$ obtained from the IL tests reduces more gently with depth from $2 \times 10^{-9}$ to $2 \times 10^{-10} \mathrm{~m} / \mathrm{s}$. The largest values of $c_{\mathrm{v}}$ and $k_{\mathrm{w}}$ in the CRS tests were obtained on specimens located between 1.0 and $2.0 \mathrm{~m}$ depth which, according to the $\mathrm{CT}$ images shown in Fig. 2, represents a heterogeneous zone composed either of sandy/clayey silts (Inclo 2) or clayey/silty sands (Mex 9) with the presence of roots that are preferential paths for fluid flow during loading. Good agreement is observed between in situ and laboratory estimations for both $c_{\mathrm{v}}\left(\right.$ or $\left.c_{\mathrm{h}}\right)$ and $k_{\mathrm{w}}$. In situ values of $c_{\mathrm{h}}$ and $k_{\mathrm{w}}$ were estimated from CPTu dissipation tests as well as from BAT permeability tests, respectively.

\section{UNDRAINED SHEAR STRENGTH}

The undrained shear strength along the soil profile was evaluated from undrained triaxial (compression and extension) tests. These tests were carried out in two hydraulic stress path cells (Imperial College, London) and one set of commercial stress path equipment (GDS Instruments). In all cases, the tests were controlled using the system developed by Toll \& Ackerley (1988). Specimens $50 \mathrm{~mm}$ in diameter and $100 \mathrm{~mm}$ high were trimmed in a soil lathe using a very thin wire saw. Synthetic pore fluid at the same EC as the natural clay was used in most tests, but a few were carried out using deionised water (see Table 4). In the latter case, the final EC was checked at the end of the test and showed a small reduction in EC due to the small amount of water injected into the specimens during back-saturation. Each triaxial test consisted of three stages: $(a)$ saturation; $(b)$ consolidation; and $(c)$ shearing under undrained conditions. A stresscontrolled saturation ramp was applied until the cell pressure and back-water-pressure reached 510 and $500 \mathrm{kPa}$, respectively. This stress state was maintained for around $30 \mathrm{~h}$, and then Skempton's parameter $B$ was checked and found to be higher than 0.96 in all cases. Most specimens followed anisotropic consolidation, using values of $K_{0}$ estimated from SDMT and CPTu tests, until $\sigma_{\mathrm{v} 0}^{\prime}$ was reached (Fig. 1(b)). $K_{0}$ consolidation was applied in two steps. The deviatoric 

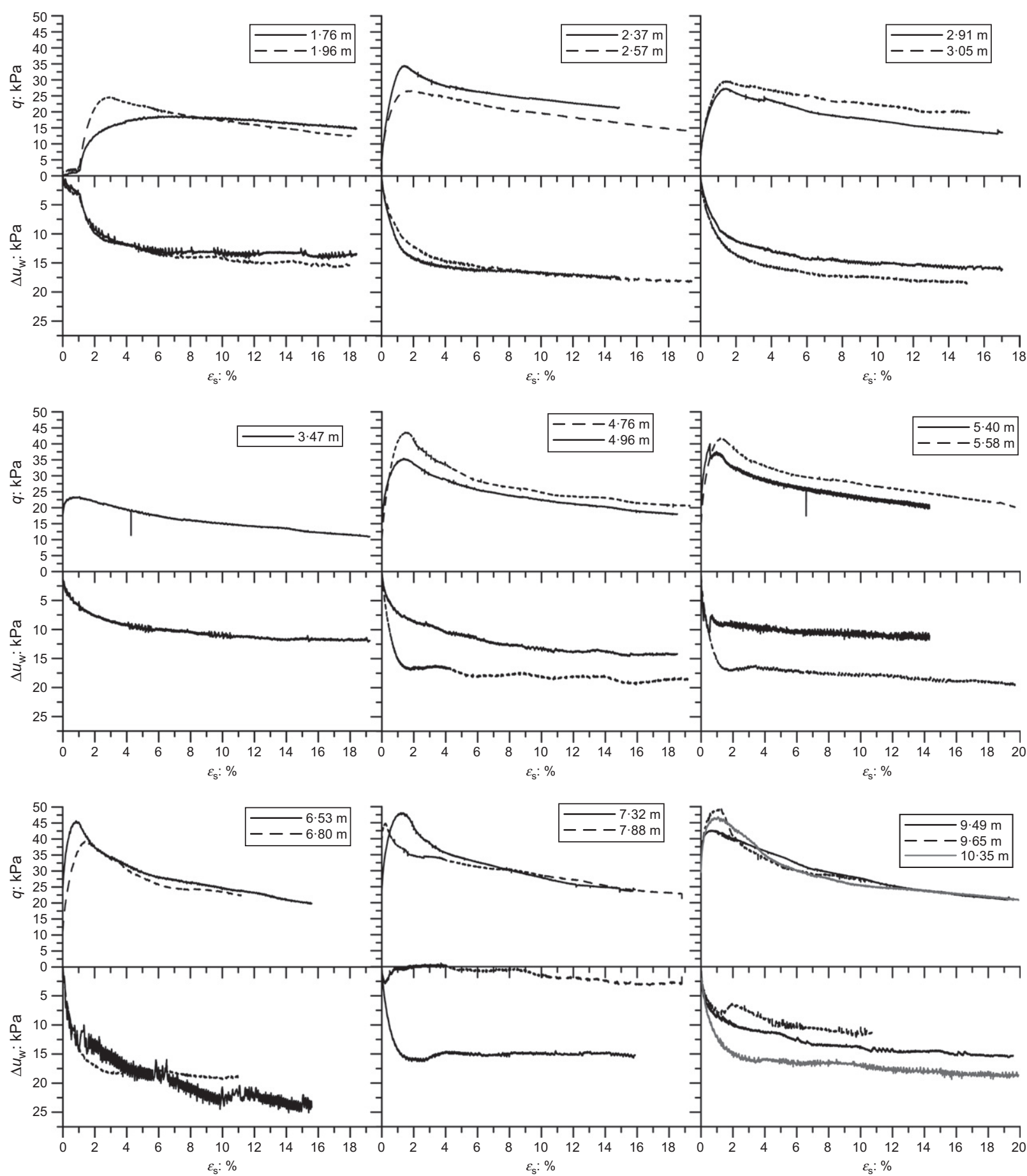

Fig. 14. Stress-strain-pore pressure curves for specimens from Inclo 2 subjected to undrained (compression) shearing

stress, $q$, was increased to achieve a target value of $\eta=3$ $\left(1-K_{0}\right) /\left(1+2 K_{0}\right)$, which was followed then until $\sigma_{\mathrm{v} 0}^{\prime}$ was reached. A few tests followed consolidation under zero lateral deformation conditions $\left(\Delta \varepsilon_{\mathrm{r}}=0\right)$ as indicated in Table 4 . Axial strains were estimated using an external linear variable differential transducer (LVDT), whereas volumetric strains were determined using a volume gauge device. In all cases, the specimens were consolidated using an axial loading rate of $12 \mathrm{~N} /$ day. Pore water drainage was provided at the bottom of the specimen and excess pore water pressure was measured using a pore pressure transducer connected to the top drainage line. At the end of the consolidation stage, each sample was subjected to undrained shearing, either axial compression or axial extension, using an axial strain rate equal to $5 \% /$ day.
The consolidation criterion followed in the triaxial tests was based on the dissipation of at least $90 \%$ of the excess pore water pressure. A maximum excess pore water pressure of $9 \mathrm{kPa}$ was registered during consolidation, irrespective of the sample depth. The excess pore water pressure dissipated typically after 4-5 days. During this process the axial strain rate reduced below $0 \cdot 004 \% / \mathrm{h}$. Results from triaxial tests have been corrected to consider the strength and stiffness of the rubber membrane. The initial conditions of the tested specimens, as well as a summary of the triaxial results, are given in Table 4.

\section{Stress-strain behaviour}

Figure 14 shows the stress-strain curves, $q-\varepsilon_{\mathrm{s}}$, obtained for specimens from borehole Inclo 2 during undrained 


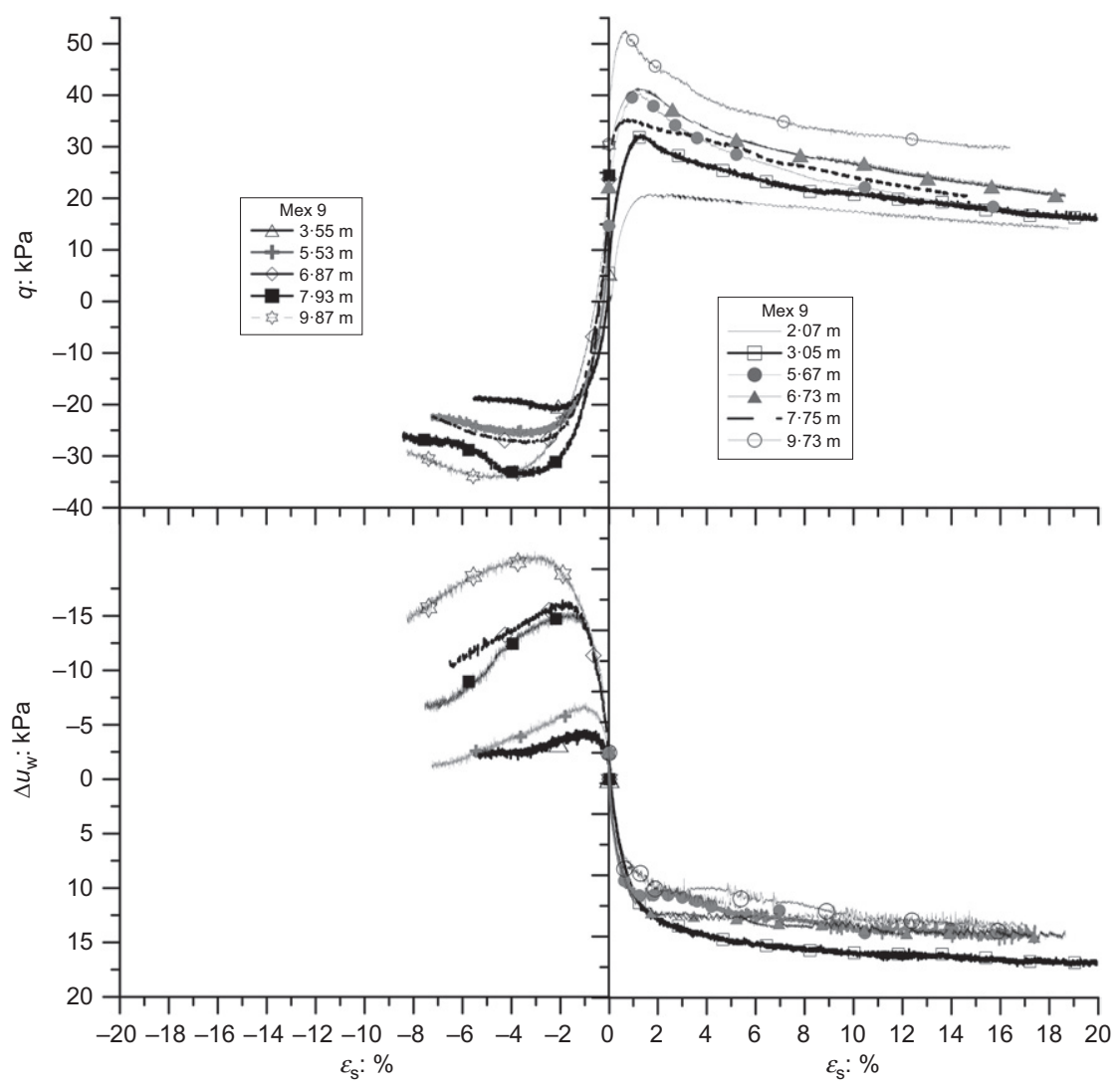

Fig. 15. Stress-strain-pore pressure curves for specimens from Mex 9 subjected to undrained (compression and extension) shearing

compression. The evolution of $\Delta u_{\mathrm{w}}$ is also included. The following observations can be made.

(a) The stress-strain curves show a brittle response, with a decrease in $q$ after reaching its peak value.

(b) The peak deviatoric stress is achieved at shear strain lower than $2 \%$, irrespective of the sample depth.

(c) The excess pore water pressure shows a similar response in specimens from similar depths; it reaches a plateau typically at shear strains higher than $6 \%$.

(d) A small excess pore water pressure was registered in specimens previously consolidated under zero radial strain conditions $(3.47 \mathrm{~m}, 4.96 \mathrm{~m}, 7.88 \mathrm{~m}$ and $9.65 \mathrm{~m})$. In these, the stress state at the end of consolidation was different (closer to the failure line) to those of the $K_{0}$-consolidated specimens, despite being recompressed to the same vertical effective stress. This aspect highlights the stress-path dependency of the volumetric soil response which, in turn, will affect the assessment of sample disturbance.

Stress-strain curves for specimens from borehole Mex 9, for both compression and extension tests, are shown in Fig. 15. These show a consistent increase in the soil stiffness and maximum deviatoric stress with increasing specimen depth. The peak deviatoric stresses are higher in triaxial compression, and brittleness is also an important feature of the stress-strain curves in specimens from borehole Mex 9. Peak conditions are achieved at shear strains lower than $1.5 \%$ in compression and up to $4 \%$ in extension. Necking was the failure mode typically observed in the triaxial extension tests. The response of the excess pore water pressure is similar for all the specimens subjected to axial compression, but this is not the case for specimens sheared under extension conditions, where the influence of the sample depth seems to be more important.

Figure 16 compares the stiffness decay curves, $G_{\mathrm{u}-\mathrm{sec}}=$ $\Delta q / 3 \Delta \varepsilon_{\mathrm{s}}$, plotted against $\varepsilon_{\mathrm{s}}$, for specimens from borehole Mex 9 sheared under compression (TC) and extension (TE) conditions. Values of the small-strain shear modulus, $G_{0}$ (BE) $\sigma^{\prime} \mathrm{v} 0$, obtained from CRS tests at $\sigma_{\mathrm{v} 0}^{\prime}$ using bender elements as well as in situ stiffness estimated from SDMT tests, are included. In addition, the stiffness decay curves for specimens from borehole Inclo 2 (solid lines) are shown for comparison. Results for five different levels down the soil profile are given in Fig. 16. There, shear stiffness has been normalised using $\sigma_{\mathrm{v} 0}^{\prime}$. These results show that the stiffness of Ballina clay is strongly non-linear and stress-path dependent. In general, the small-strain stiffness estimated from bender elements compares well with both the triaxial and SDMT data, in particular for specimens from borehole Inclo 2 . The soil stiffness decays more quickly with strain in triaxial compression, although this behaviour is clearer at strain levels smaller than $0 \cdot 1 \%$. For strains larger than $0 \cdot 1 \%$ the stiffness of the clay seems to be similar in either triaxial compression or extension with the exception of specimens located between $6.73 \mathrm{~m}$ and $7.93 \mathrm{~m}$. There, higher values have been measured in triaxial extension. Comparison between the boreholes shows a higher stiffness for specimens from borehole Mex 9, which may be attributed to differences in the natural water content (void ratio) as discussed above.

\section{Failure behaviour}

Figure 17(a) shows the variation of the stress ratio, $q / p^{\prime}$, with $\varepsilon_{\mathrm{s}}$ for specimens from borehole Inclo 2. Post-peak values of the stress ratio range from 1 to about 1.95 and, despite some scatter, the behaviour of the stress ratio can be classified 


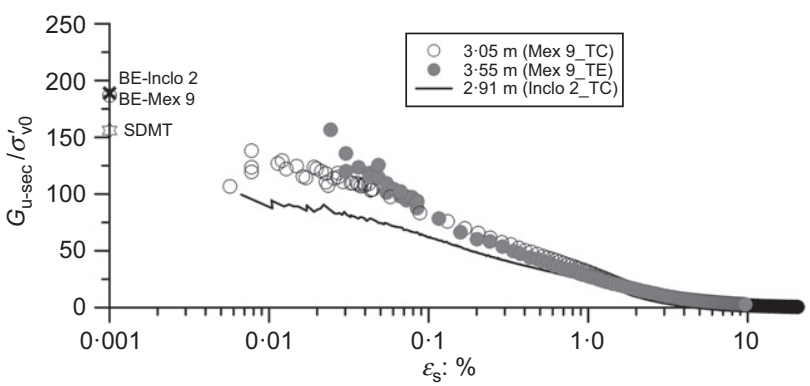

(a)

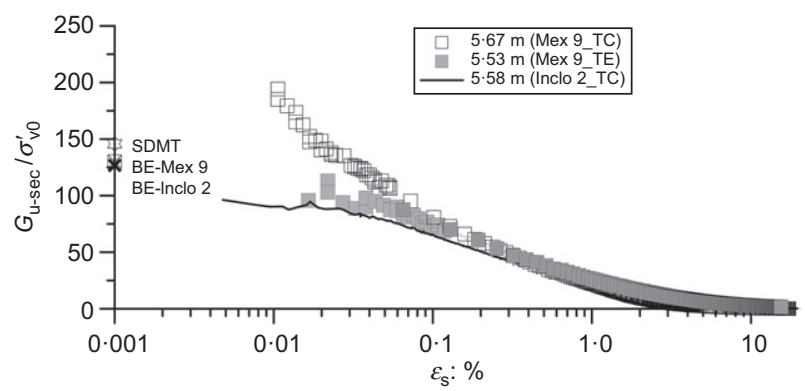

(b)

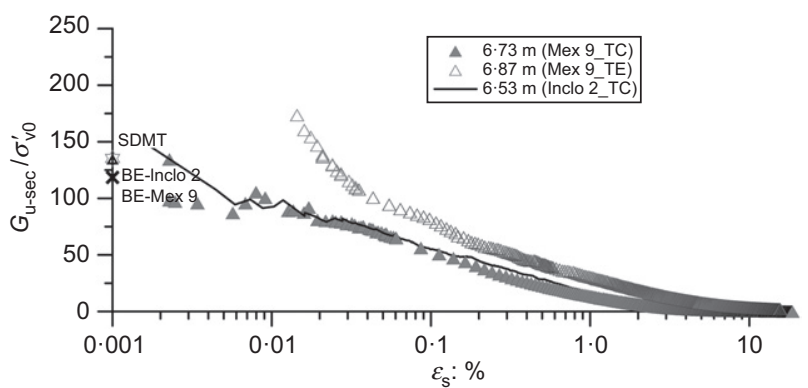

(c)

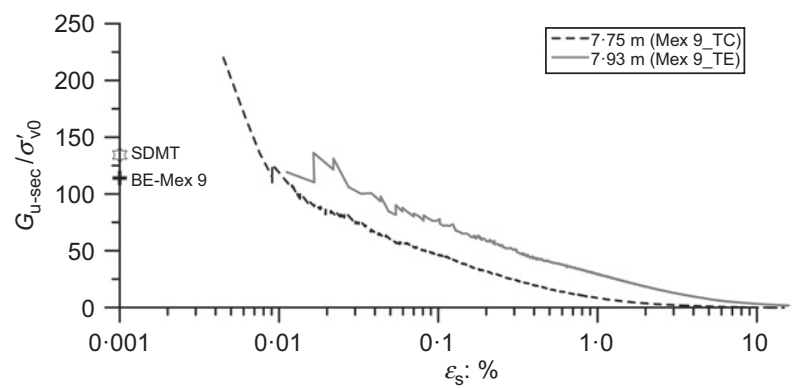

(d)

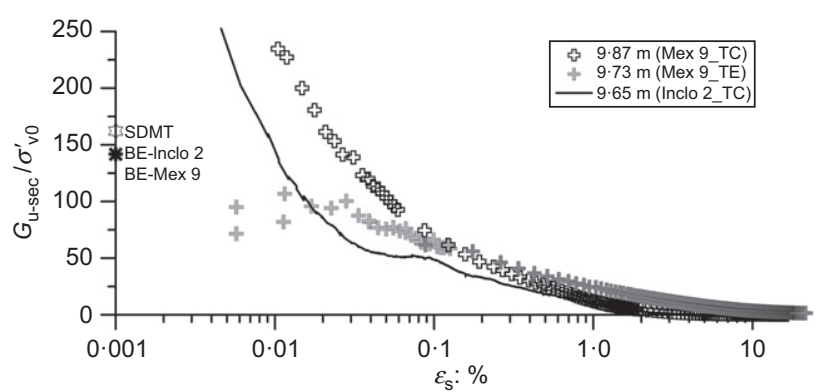

(e)

Fig. 16. Stiffness decay curves for specimens sheared under undrained compression and extension

into three main groups as observed in Fig. 17(b). There, the secant friction angle, $\phi_{\text {sec }}^{\prime}$, has been estimated for shear strains larger than $10 \%$. Average friction angles of $32^{\circ}, 36^{\circ}$ and $41^{\circ}$ seem to represent the post-peak response of specimens from Inclo 2, although there is no definite relationship between

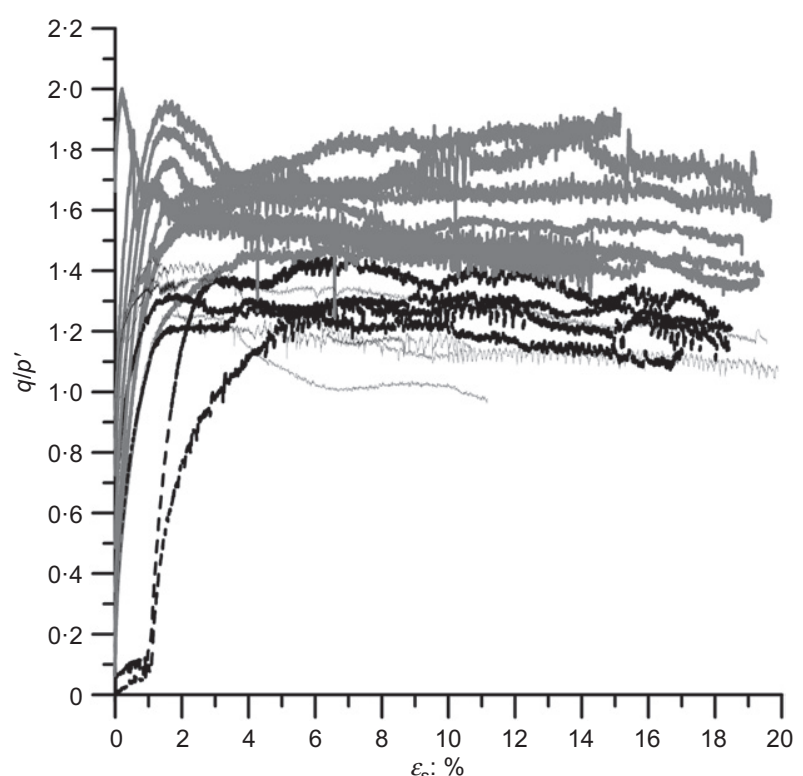

(a)

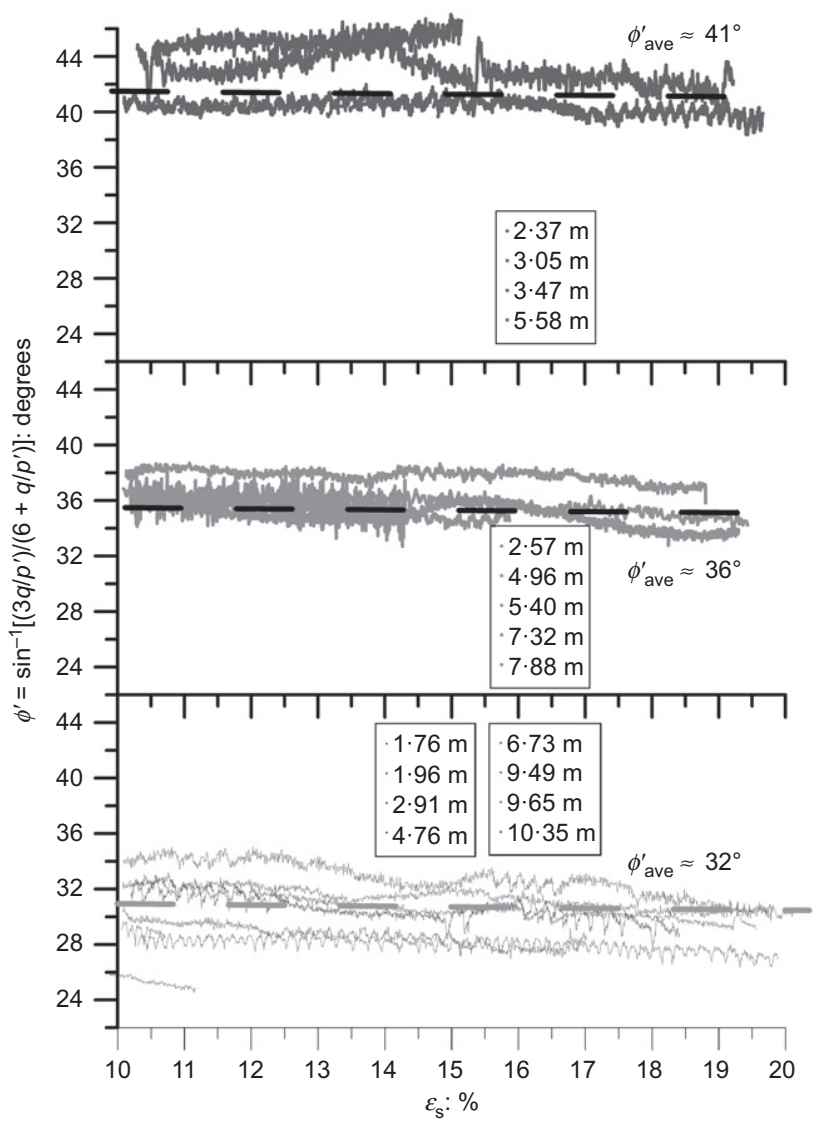

(b)

Fig. 17. Undrained shearing tests for specimens from borehole Inclo 2: (a) stress ratio, (b) secant effective friction angle

$\phi_{\mathrm{sec}}^{\prime}$ and specimen depth, which may be due to the natural variability of the soil specimens (e.g. sand content, presence of shells). Both shallow and deep specimens give some of the lowest values of $\phi_{\mathrm{sec}}^{\prime}$, whereas specimens located in the central zone of the profile $(5 \mathrm{~m}$ and $8 \mathrm{~m})$ have $\phi_{\mathrm{sec}}^{\prime} \approx 36^{\circ}$. The variation of $q / p^{\prime}$ for specimens from borehole Mex 9 (compression and extension tests) is shown in Fig. 18. Values between $1 \cdot 1$ and 1.8 were estimated in triaxial compression, which lies in the same range of variation observed 


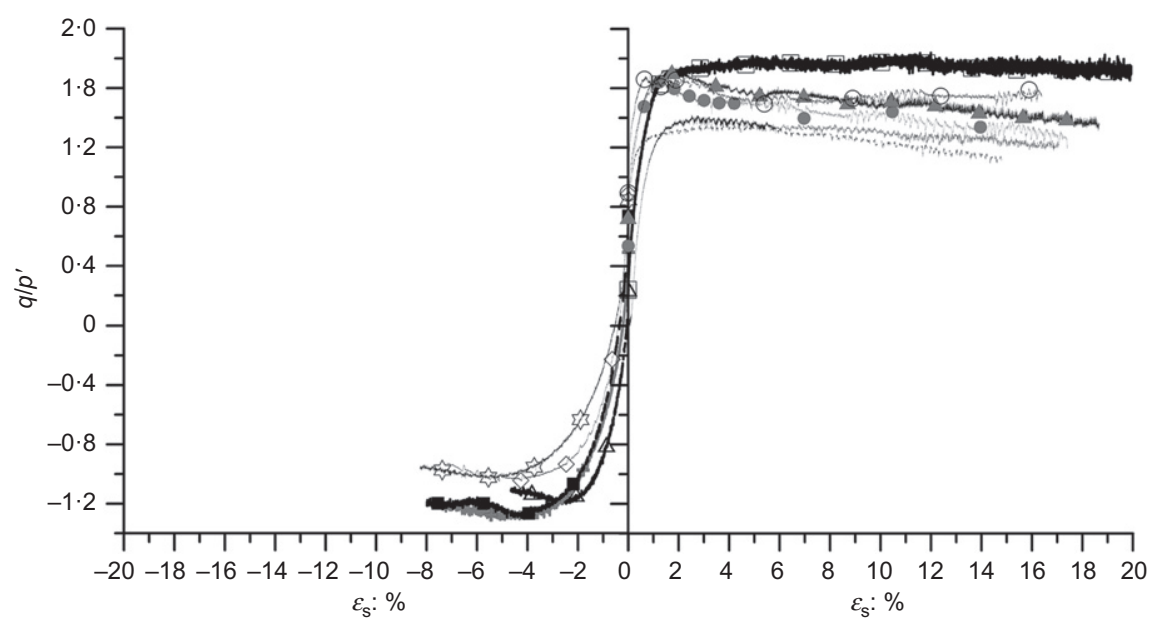

Fig. 18. Stress ratio and secant effective friction angle for specimens from borehole Mex 9 sheared in triaxial compression and extension

in specimens from borehole Inclo 2. In triaxial extension, the stress ratio ranges in a narrower band around $0 \cdot 8-1 \cdot 35$.

Figure 19 shows the stress path followed in the $q-p^{\prime}$ plane for all specimens tested in triaxial conditions. Results from four additional triaxial tests (two TC and two TE tests), performed on specimens retrieved from boreholes IGS 1 and IGS 2 (Fig. 1(b)) using a $63 \mathrm{~mm}$ direct-push piston sampler (Pineda et al., 2014) have also been included for comparison using grey solid lines. The brittleness of the soil under shearing is clearly observed in the effective stress paths presented in Fig 19. Peak friction angles between $32^{\circ}$ and $50^{\circ}$ were estimated in triaxial compression for borehole Inclo 2 . It is worth noting the marked difference between the friction angles in compression and extension for borehole Mex 9, where peak friction angles of up to $42^{\circ}$ and $53^{\circ}$ have been estimated in triaxial compression and triaxial extension, respectively. No attempts have been made to estimate the friction angle at large strains in extension due to the failure mode (necking) observed during the tests. In the absence of drained triaxial tests results, the effective stress paths shown in Fig. 19 seem to indicate asymmetry of the yield locus about the isotropic line.

On the other hand, the soil profile at the Ballina site includes two levels in which the sand content is dominant (see Fig. 3). These layers appear above $1.5 \mathrm{~m}$ and between $11.1 \mathrm{~m}$ and $12.3 \mathrm{~m}$. Owing to the difficulty in trimming high-quality triaxial specimens from these soil layers, drained shear strength parameters were obtained from direct shear tests using samples $(70 \mathrm{~mm}$ in diameter) consolidated prior to shearing under vertical stresses of 25 , 50 and $100 \mathrm{kPa}$. Table 5 summarises the initial conditions of the specimens used in the direct shear tests, as well as values of effective cohesion and friction angle estimated by assuming a linear failure criterion. The shallow materials showed a peak friction angle of $\phi_{\text {peak }}^{\prime} \approx 34^{\circ}$ and an effective cohesion of $15 \mathrm{kPa}$, whereas the deep specimens displayed a peak friction angle of $\phi_{\text {peak }}^{\prime} \approx 38^{\circ}$ and a zero cohesion intercept.

\section{Variation of $\mathrm{s}_{u}$ with depth}

Figure 20(a) shows the variation of the undrained shear strength, $s_{\mathrm{u}}=q_{\text {peak }} / 2$, with depth for boreholes Inclo 2 and Mex 9. Results from the triaxial compression and triaxial extension tests are indicated by filled and empty symbols, respectively. It can be seen that there is a progressive increase in $s_{\mathrm{u}}$ with depth, not only in compression but also under extension shearing conditions. Good agreement is observed

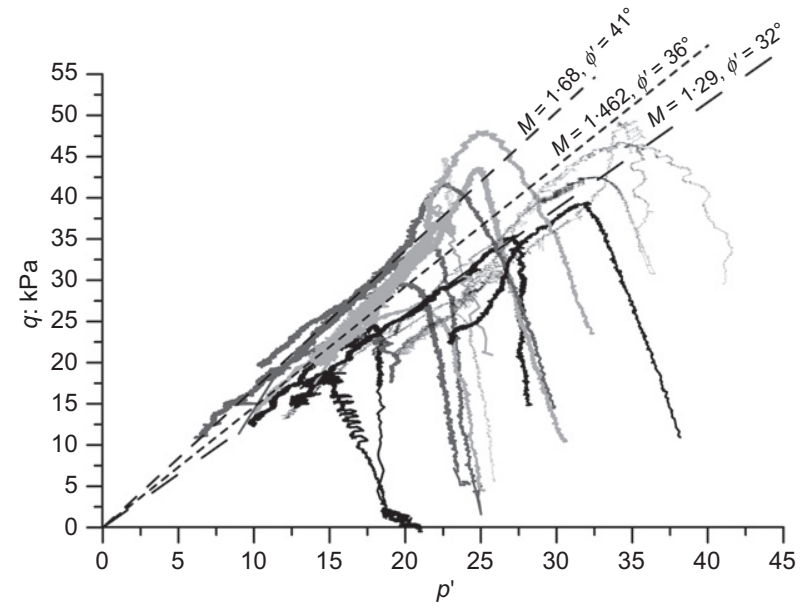

(a)

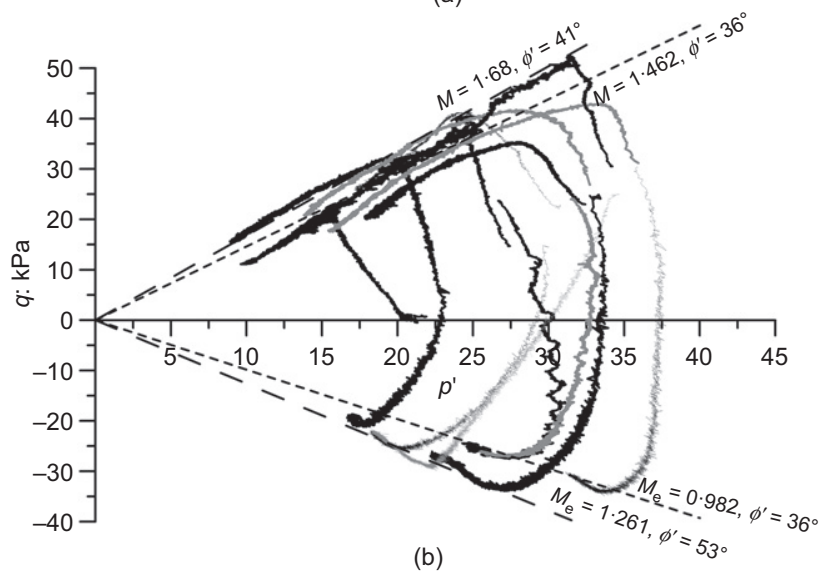

Fig. 19. Effective stress paths: (a) specimens from borehole Inclo 2; (b) specimens from borehole Mex 9

between boreholes Inclo 2 and Mex 9 (compression tests). The strength $s_{\mathrm{u}}$ lies around $12.5 \mathrm{kPa}$ at $1.8 \mathrm{~m}$ depth, and increases up to $27.5 \mathrm{kPa}$ at a depth of $9.75 \mathrm{~m}$. It increases almost linearly with depth in triaxial extension from $10.5 \mathrm{kPa}$ to $17.5 \mathrm{kPa}$ between the depths of $3.5 \mathrm{~m}$ and $10 \mathrm{~m}$. Results from in situ tests are also reported in Fig. 20(a). These include CPTu, SDMT and field vane (FVS) tests performed at the locations indicated in Fig. 1(a). Values of $s_{\mathrm{u}(\mathrm{CPTU})}$ were 'calibrated' to the shear vane data using $N_{\mathrm{kt}}=13 \cdot 2$. The laboratory results show a good match 
with those from the in situ tests, in particular with the $s_{\mathrm{u}}$ results obtained from FVS, SDMT-1 and CPTu. Slightly higher values of $s_{\mathrm{u}}$ are observed in the triaxial data for samples between 5 and $8 \mathrm{~m}$ depth. Triaxial results have been used to estimate the rigidity index, $I_{\mathrm{r}}=G_{\mathrm{u} 50} / s_{\mathrm{u}}$, which can be used to predict the horizontal consolidation coefficient, $c_{\mathrm{h}}$, from dissipation stages in CPTu testing (see Fig. 20(b)). The rigidity index increases with depth from 25 to 150, although most of the data lie in the range 65-150. Despite some scatter, the variation of $I_{\mathrm{r}}$ with depth seems to be linear below a depth of $3 \mathrm{~m}$. The lowest $I_{\mathrm{r}}$ refers to silty/sandy clays located at shallow depths, as observed in Figs 2 and 3.

\section{CONCLUDING REMARKS}

The laboratory characterisation of the Ballina clay from the National Field Testing Facility in NSW (Australia) has been described in this paper. Ballina clay represents estuarine soft clay of high to extremely high plasticity, and it is structured and lightly overconsolidated with an organic content of around 3\%. It is composed of kaolinite, illite, quartz, interstratified illite/smectite and amorphous

Table 5. Summary of drained shear tests on sandy materials

\begin{tabular}{l|c|c|c|c}
\hline Depth: $\mathrm{m}$ & $e_{0}$ & $w_{0}: \%$ & $c^{\prime}: \mathrm{kPa}$ & $\phi^{\prime}:$ degrees \\
\hline $0 \cdot 5-1 \cdot 0$ & $0 \cdot 9-1 \cdot 0$ & $30 \cdot 4-31 \cdot 8$ & 15 & 34 \\
$11 \cdot 1-11 \cdot 7$ & $0 \cdot 73-0 \cdot 80$ & $25 \cdot 1-26 \cdot 2$ & 5 & 38 \\
$11 \cdot 7-12 \cdot 3$ & $0 \cdot 67-0 \cdot 70$ & $23 \cdot 4-24 \cdot 2$ & 0 & 39 \\
\hline
\end{tabular}

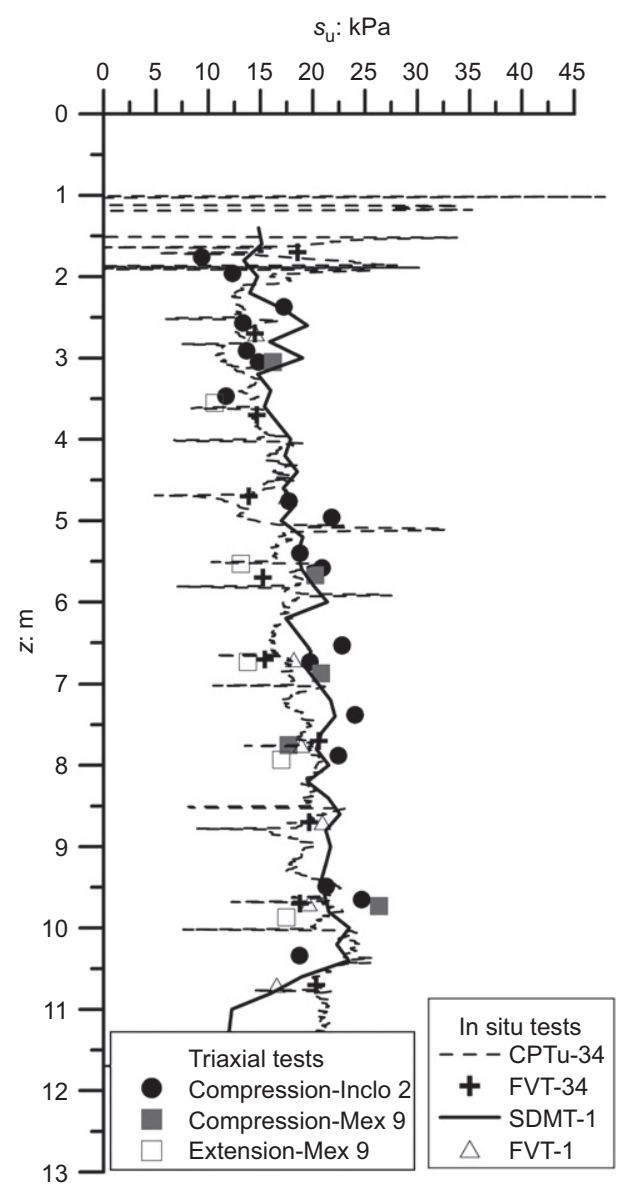

(a) minerals. The clay fraction is predominant below $2 \mathrm{~m}$ depth; the sand content is almost negligible between $2 \mathrm{~m}$ and $11 \cdot 1 \mathrm{~m}$. The presence of shells, randomly distributed along the soil profile, is common for depths above $4.5 \mathrm{~m}$. The homogeneity of the clay below $4.5 \mathrm{~m}$ seems to indicate a change in soil structure. The pore water is saline in Ballina clay and seems to play a key role in its mechanical behaviour. The concentration of sodium chloride in the pore fluid may reach $24 \mathrm{~g} / 1$, more than half the concentration in seawater, which supports the use of synthetic pore fluid during mechanical tests.

The initial location of the compressibility curves in the $I_{\mathrm{v}}-\log \sigma_{\mathrm{v}}^{\prime}$ plane with respect to the ICL curve gives an indication of the natural structure in Ballina clay. The compressibility curves converge to the ICL due to progressive soil destructuration during one-dimensional loading. The compression curve is strongly non-linear, which means that $C_{\mathrm{c}}$ reduces with the stress level. Yield stress ratio reduces with depth, from around 3 at shallow depths towards 1.5 below $5 \mathrm{~m}$. The consolidation coefficient reduces as the stress level approaches $\sigma_{\text {yield. }}^{\prime}$ It shows typical values of $0 \cdot 3-0.5 \mathrm{~m}^{2} /$ year in the normally consolidated range. Similarly, $k_{\mathrm{w}}$ reduces as the void ratio decreases. Larger values were measured in specimens from borehole Mex 9. The permeability decreases by around two orders of magnitude to values of about $10^{-11} \mathrm{~m} / \mathrm{s}$ in the normally consolidated stress range. Results from the creep tests indicated that Ballina clay exhibits secondary compression, with the ratio $C_{\alpha} / C_{\mathrm{c}}$ varying in the range of $0 \cdot 03-0 \cdot 05$.

A brittle stress-strain response was observed in undrained shearing tests, which caused a post-peak reduction of around

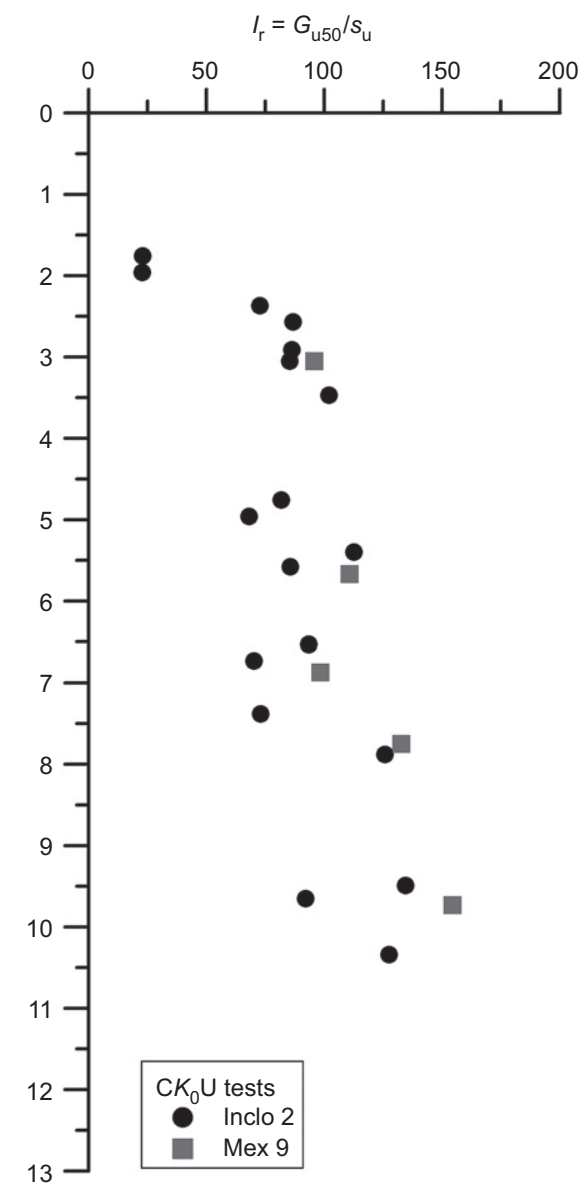

(b)

Fig. 20. Profiles of: (a) $s_{\mathrm{u}}$ and (b) $I_{\mathrm{r}}$ with depth 
$50 \%$ in the deviatoric stress. This behaviour is attributed mainly to soil destructuration. Strains at peak were smaller in the triaxial compression tests than in the triaxial extension tests. The stiffness of the clay shows strong non-linearity and stress-path dependency. It decays quickly in triaxial compression, although this behaviour is more pronounced at strain levels below $0 \cdot 1 \%$. High friction angles were measured for the natural clay, with values lying between $32^{\circ}$ and $42^{\circ}$ at large strains. Results from undrained triaxial tests suggest asymmetry of the yield locus about the isotropic line, although no attempts have been made here to quantify the anisotropy of the natural clay.

Tube specimens were used for the characterisation programme as it is the most common sampling method in soft soils worldwide. Although soil disturbance due to tube sampling may not be totally avoided, the results described above have shown that the use of large-diameter fixed piston samplers, in combination with non-destructive methods to assess and select samples for laboratory testing, provide good quality and reliable tests results which are in agreement with those estimated from in situ tests (e.g. $V_{\mathrm{s}}$ and $s_{\mathrm{u}}$ ). The results of the characterisation study described above have been used in a companion paper to develop a geotechnical model for Ballina clay by combining high-quality in situ and laboratory data.

\section{ACKNOWLEDGEMENTS}

The authors are grateful for support by all contributing partners to the ARC Centre of Excellence for Geotechnical Sciences and Engineering at the University of Newcastle, Australia. These partners include Advanced Geomechanics, Coffey Geotechnics and Douglas Partners. The third author also acknowledges the funding provided by the NSW Science Leveraging Fund.

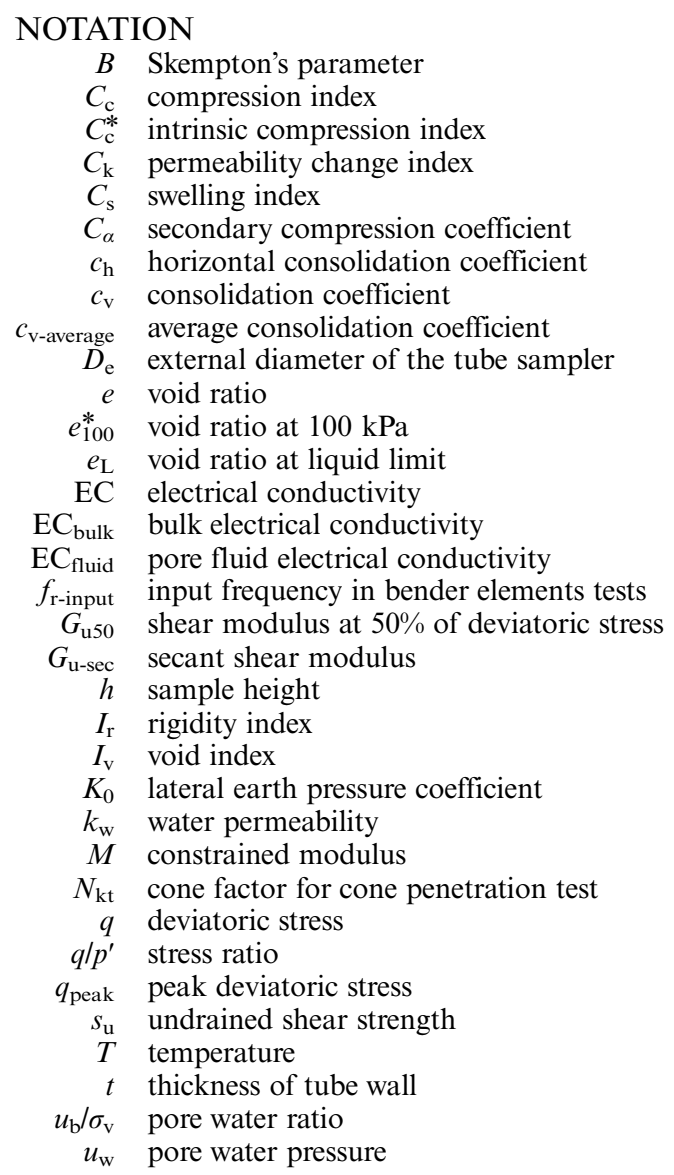

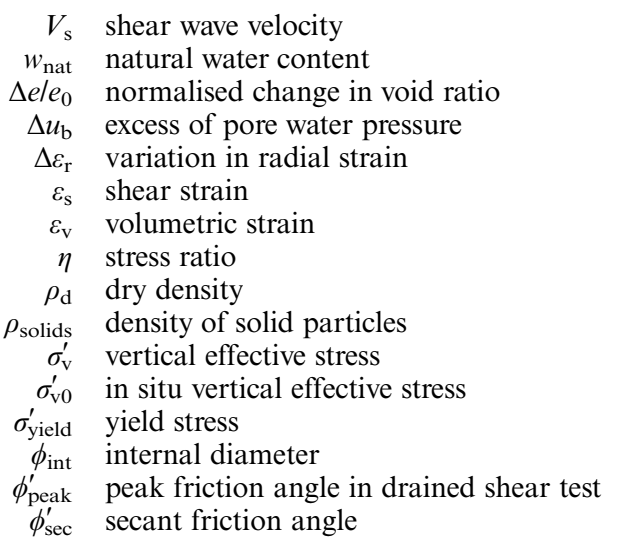

\section{REFERENCES}

APHA (American Public Health Association) (2012). Standard methods for the examination of water and wastewater, 22nd edn. Denver, CO, USA: American Water Works Association.

ASTM (2006). ASTM D4186: Standard test method for onedimensional consolidation properties of saturated cohesive soils using controlled-strain loading. West Conshohocken, PA, USA: ASTM International.

ASTM (2011). ASTM D2435: Standard test methods for onedimensional consolidation properties of soils using incremental loading. West Conshohocken, PA, USA: ASTM International.

Becker, D. E., Crooks, J. H. A., Ben, K. \& Jefferies, M. G. (1987). Work as a criterion for determining in situ and yield stresses in clays. Can. Geotech. J. 24, No. 4, 549-564.

Bishop, D. T. (2004). A proposed geological model and geotechnical properties of a NSW estuarine valley: a case study. Proceedings of the 9th ANZ conference, Auckland, New Zealand, pp. 261-267.

Bishop, D. T. \& Fityus, S. (2006). The sensitivity framework: behaviour of Richmond River estuarine clays. Proceedings of mini-symposium, Sydney, Australia, pp 167-178. St Ives, NSW, Australia: Australian Geomechanics Society.

Burland, J. B. (1990). On the compressibility and shear strength of natural clays. Géotechnique 40, No. 3, 329-378, http://dx.doi. org/10.1680/geot.1990.40.3.329.

Carrier, W. D. \& Beckman, J. F. (1984). Correlations between index tests and the properties of remoulded clays. Géotechnique $\mathbf{3 4}$, No. 2, 211-228, http://dx.doi.org/10.1680/geot.1984.34.2.211.

Carrier, W. D. \& Beckman, J. F. (1985). Consolidation parameters derived from index tests. Géotechnique 35, No. 2, 211-213, http:// dx.doi.org/10.1680/geot.1985.35.2.211.

Gimias (2011). Graphical interface for medical image analysis and simulation, Gimias_v1.2.0. Barcelona, Spain: Centre for Computational Image and Simulation Technologies in Biomedicine (CISTIB)/Universitat Pompeu Fabra (UPF). See http://www.gimias.org (accessed 18/02/2016).

Hight, D. W., Bond, A. J. \& Ledge, J. D. (1992). Characterization of the Bothkennar clay: an overview. Géotechnique 42, No. 2, 303-347, http://dx.doi.org/10.1680/geot.1992.42.2.303.

Kelly, R. B. (2013). Australia's first national facility for soft soils testing. Civ. Engrs Aust. June, 76-78.

Kelly, R. B., Mayne, P. W. \& Pineda, J. A. (2013). In situ and laboratory testing of soft clays. Aust. Geomech. 48, No. 3, 61-72.

Kouretzis, G., Ansari, Y., Pineda, J. A., Kelly, R. \& Sheng, D. (2015). Numerical evaluation of clay disturbance during blade penetration, considering the effect of stress history. Géotechnique Lett. 5, No. 3, 91-95.

Ladd, C. C. \& DeGroot, D. J. (2003). Recommended practice for soft ground site characterization: Arthur Casagrande Lecture. In Proceedings of the 12th pan American conference on soil mechanics and geotechnical engineering (eds P. J. Culligan, H. H. Einstein and A. J. Whittle), vol. 1, pp. 3-57. Essen, Germany: Verlag Glückauf GmbH.

Leroueil, S., Tavenas, F. \& Le Bihan, J. P. (1983) Propriétés caractéristiques des argiles de l'est du Canada. Can. Geotech. J. 20, No. 4, 681-705 (in French).

Lunne, T., Berre, T. \& Strandvik, S. (1997). Sample disturbance effects in soft low plasticity Norwegian clay. In Proceedings of 
symposium on recent developments in soil and pavement mechanics, Rio de Janeiro, Brazil (ed M. Almedia), pp 81-92. Rotterdam, the Netherlands: Balkema.

Mayne, P. W. (2007). Cone penetration testing. State-of-practice, NCHRP Project 20-05. Washington, DC, USA: Transportation Research Board.

Mesri, G. \& Choi, Y. K. (1985) Settlement analysis of embankments on soft clays. J. Geotech. Engng 111, No. 4, 441-464.

Mesri, G. \& Feng, T. W. (1992). Constant rate of strain consolidation testing of soft clays. Proceedings of Marsal symposium, Mexico City, Mexico, pp. 49-59. Mexico City, Mexico: Sociedad Mexicana de Mecánica de Suelos.

Mesri, G. \& Godlewski, P. M. (1977). Time-stress-compressibility interrelationship. Proc. Geochem. Div. Am. Soc. Civ. Engrs, Civ. Engng 22, No. 5, 417-430.

Mitchell, J. K. (1976). Fundamentals of soil behaviour. New York, NY, USA: Wiley \& Sons.

Moore, D. M. \& Reynolds, R. C. (1997). X-ray diffraction and the identification and analysis of clay minerals. Oxford, UK: Oxford University Press.

Pineda, J. A., Arroyo, M., Sau, N., Gens, A. \& Pérez, N. (2012). Testing block samples from silty deposits. In Proceedings of geotechnical and geophysical site characterization 4 (eds R. Q. Coutinho and P. W. Mayne), pp 1815-1823. London, UK: Taylor \& Francis Group.
Pineda, J. A., Kelly, R., Bates, L., Sheng, D. \& Sloan, S. (2013). Effects of pore fluid salinity on the shear strength of a soft clay. In Poromechanics V: Proceedings of the 5th biot conference in poromechanics (eds C. Hellmich, B. Pichler and D. Adam), pp. 1460-1469. Reston, VA, USA: American Society of Civil Engineers.

Pineda, J. A., McConnell, A. \& Kelly, R. B. (2014). Performance of an innovative direct-push piston sampler in soft clay. In Proceedings of the 3rd symposium on cone penetration testing (eds P. K. Robertson, K. L. Cabal and R. E. S. Moss), pp 279-288. Las Vegas, NV, USA: CPT14 Press.

Skempton, A. W. (1953). The colloidal activity of clays. Proceedings of 3rd international conference on soil mechanics, Zurich, Switzerland, vol. 1, pp 57-61.

Skempton, A. W. (1954). Discussion of the structure of inorganic soil. Proc. ASCE, Soil Mech. Found. Div. 80, No. 478, 19-22.

Toll, D. G. \& Ackerley, S. K. (1988). The development of two data acquisition systems for a geotechnical laboratory. Proceedings of international symposium on new concepts in laboratory and field tests in geotechnical engineering, vol. 2, pp. 453-456. Rio de Janeiro, Brazil: Brazilian Society for Soil Mechanics and Foundation Engineering.

Watabe, Y., Udaka, K., Nakatani, Y. \& Leroueil, S. (2012). Long-term consolidation behaviour interpreted with isotache concept for worldwide clays. Soils Found. 52, No. 3, 449-464. 